OPEN ACCESS

Edited by:

Betty Diamond,

Feinstein Institute for Medical

Research, United States

Reviewed by:

Yogesh M. Scindia,

University of Florida, United States

Laurence Morel,

University of Florida, United States

*Correspondence:

Carolina Llanos

cllanos@med.puc.cl

Specialty section:

This article was submitted to Autoimmune and Autoinflammatory

Disorders,

a section of the journal

Frontiers in Immunology

Received: 30 May 2019 Accepted: 22 November 2019 Published: 13 December 2019

Citation:

Cuitino L, Obreque J, Gajardo-Meneses $P$, Villarroel $A$, Crisóstomo N, San Francisco IF, Valenzuela RA, Méndez GP and Llanos C (2019) Heme-Oxygenase-1 Is Decreased in Circulating Monocytes

and Is Associated With Impaired Phagocytosis and ROS Production in

Lupus Nephritis.

Front. Immunol. 10:2868.

doi: 10.3389/fimmu.2019.02868

\section{Heme-Oxygenase-1 Is Decreased in Circulating Monocytes and Is Associated With Impaired Phagocytosis and ROS Production in Lupus Nephritis}

\author{
Loreto Cuitino ${ }^{1}$, Javiera Obreque ${ }^{1}$, Patricia Gajardo-Meneses ${ }^{1}$, Alejandra Villarroel ${ }^{2}$, \\ Natalia Crisóstomo ${ }^{1}$, Ignacio F. San Francisco ${ }^{3}$, Rodrigo A. Valenzuela ${ }^{4}$, \\ Gonzalo P. Méndez ${ }^{2}$ and Carolina Llanos ${ }^{\text {* }}$
}

${ }^{1}$ Departamento de Inmunología Clínica y Reumatología, Escuela de Medicina, Pontificia Universidad Católica de Chile, Santiago, Chile, ${ }^{2}$ Departamento de Anatomía Patológica, Escuela de Medicina, Pontificia Universidad Católica de Chile, Santiago, Chile, ${ }^{3}$ Departamento de Urología, Escuela de Medicina, Pontificia Universidad Católica de Chile, Santiago, Chile, ${ }^{4}$ Departamento de Ciencias Químicas y Biológicas, Facultad de Salud, Universidad Bernardo O'Higgins, Santiago, Chile

Lupus nephritis $(L N)$ is one of the most serious manifestations of systemic lupus erythematosus (SLE). Based on studies showing the potential role of heme oxygenase-1 (HO-1), an enzyme that catalyzes the degradation of heme and has anti-inflammatory properties in SLE development, we decided to explore HO-1 in LN. Accordingly, we evaluated $\mathrm{HO}-1$ levels and function in circulating and infiltrating monocytes and neutrophils of LN patients. HO-1 levels were assessed in peripheral monocytes of LN patients and controls by flow cytometry and immunofluorescence microscopy. Phagocytosis and the production of reactive oxygen species (ROS) were evaluated to determine the effect of $\mathrm{HO}-1$ in monocyte function. In addition, renal biopsies with proliferative LN were used to identify $\mathrm{HO}^{-1}$ in infiltrating cells and renal tissue by immunofluorescence and immunohistochemistry. Biopsies of healthy controls $(\mathrm{HC})$ and patients who underwent nephrectomy were included as controls. Circulating pro-inflammatory monocytes and activated neutrophils were increased in LN patients. $\mathrm{HO}-1$ levels were decreased in all subsets of monocytes and in activated neutrophils. LN monocytes showed increased phagocytosis and higher production of ROS than those of $\mathrm{HC}$. When $\mathrm{HO}-1$ was induced, phagocytosis and ROS levels became similar to those of $\mathrm{HC}$. HO-1 was mostly expressed in renal tubular epithelial cells (RTEC). Renal tissue of $\mathrm{LN}$ patients showed lower levels of $\mathrm{HO}-1$ than $\mathrm{HC}$, whereas infiltrating immune cells of LN showed lower levels of $\mathrm{HO}-1$ than biopsies of patients who had renal surgery. $\mathrm{HO}-1$ is decreased in circulating monocytes and activated neutrophils of $\mathrm{LN}$ patients. $\mathrm{HO}-1$ levels modulate the phagocytosis of $\mathrm{LN}$ monocytes and ROS production. $\mathrm{HO}-1$ expression in RTEC might be an attempt of self-protection from inflammation.

Keywords: lupus nephritis, monocytes, heme oxygenase-1 (HO-1), phagocytosis, reactive oxygen species (ROS), renal biopsies 


\section{INTRODUCTION}

Systemic lupus erythematosus (SLE) is a chronic autoimmune disease of unknown etiology that predominantly affects women in childbearing age and is associated with higher rates of mortality than the general population. Although in SLE, inflammation may affect multiple organs, lupus nephritis (LN) remains the focus of attention of clinical and basic scientists given that kidney involvement is a major predictor of morbidity and mortality $(1,2)$. Indeed, despite efforts to improve clinical outcomes, remission is achieved in only $50-70 \%$ of LN patients and $10-20 \%$ of them will progress to end-stage renal disease (ESRD) within 5 years of diagnosis. Therefore, the better understanding of the underlying mechanisms of kidney involvement would be a progress in the field that can potentially lead to the development of new therapeutic targets.

Heme oxygenase-1 (HO-1) is an enzyme that catalyzes the degradation of heme and has anti-inflammatory properties. We have previously evaluated HO-1 expression in circulating monocytes of SLE patients, finding that this enzyme is decreased in affected individuals (3) and in an animal model for SLE (4). HO-1 can be induced in human endothelial cells after the release of strong immunogenic cytokines, such as tumor necrosis factor (TNF)- $\alpha$ and interleukin (IL)- $1 \alpha(5-7)$ and is required for the regulation of the immune response, with subsequent inhibition of pro-inflammatory signals and recovery of homeostasis (8, 9). Interestingly, when MRL-Fas ${ }^{l p r}$ lupus mice are treated with carbon monoxide (CO) - a bystander product and inducer of HO-1 expression-they present lower levels of circulating antidsDNA and anti-histone antibodies than untreated mice. In addition, kidneys from CO-treated lupus mice have less number of activated $\mathrm{B} 220^{+} \mathrm{CD} 4^{-} \mathrm{CD} 8^{-} \mathrm{T}$ cells than control animals and present delayed renal failure (4). Although it is well-known that, in LN, renal damage is initiated by glomerular deposition of immune complexes (IC) and subsequent complement activation, it has been acknowledged that innate immune cells also play an active role in the propagation of tissue damage. Recent data show that LN patients poorly degrade neutrophil extracellular traps (NETs), which promote the presentation of self-antigens (10). Even more, elegant experiments using a humanized lupus mouse model show that SLE human serum is capable of inducing LN in a process mediated by infiltrating neutrophils recruited by an Fc $\gamma$ RIIA-dependent mechanism (11).

On the other hand, monocytes have been less studied than neutrophils but are well-known to participate in SLE pathogenesis. Indeed, expanding data have demonstrated that infiltrating monocytes and macrophages are phenotypically altered in SLE and are associated with both murine and human LN (12-15). In humans, monocytes have been divided into three subtypes based on relative surface expression of lipopolysaccharide (LPS) coreceptor CD14 and FC $\gamma$ III receptor CD16, "classical" monocytes, "intermediate" monocytes, and "pro-inflammatory" monocytes. Several reports suggest that the primary function of majority of circulating monocytes is phagocytosis $(16,17)$ of cellular debris, pathogens, and other external agents in a way that does not involve the release of inflammatory mediators; however, it has been observed that monocytes of SLE patients are inefficient in the clearance of apoptotic cells, which is also associated with the production of pro-inflammatory cytokines such as IL-6, TNF- $\alpha$, IL-10, transforming growth factor (TGF)- $\beta$, and interferon (IFN)$\alpha(18-20)$.

Given our findings in circulating human monocytes and the interesting results obtained after treating lupus mice with $\mathrm{CO}$, we decided to explore whether HO-1 levels of circulating and infiltrating monocytes play a role in the pathogenesis of human LN, with a special focus on the renal interstitium because it has recently been considered an important predictor of renal outcomes in LN patients (21). In addition, we also evaluated HO-1 levels in circulating neutrophils.

\section{METHODS}

\section{Patients}

This study was approved by the Research Ethics Committee (REC) of Pontificia Universidad Católica de Chile (PUC). All subjects signed PUC-REC-approved consent forms. A total of 15 subjects who met the American College of Rheumatology SLE 1997 criteria and had a renal biopsy showing type III, IV, and/or $\mathrm{V} \mathrm{LN}$ as per the ISN/RPS classification were included to do peripheral blood and purified monocyte analyses; data of patients are shown in Table 1 (LN-1-LN-15). Fifteen healthy controls (HC) were recruited to analyze peripheral blood samples; demographic data are summarized in Table 2.

Twenty renal biopsies with type III, IV, and/or V LN ISN/RPS classification performed between January 2006 and January 2017 were used for immunofluorescence and immunohistochemistry studies (Table 1, LN-09-LN-28). A summary of histologic characteristics of renal biopsies is shown in Table 3. Biopsies of three patients who underwent surgery and nephrectomy had to be performed as part of the surgical protocol for different reasons, but their kidneys were healthy and were included as HC. Biopsies of eight patients without autoimmune disease who had renal cancer and underwent nephrectomy were included [cancer controls (CC)]. Only tissue that did not present tumor was used for the purpose of this study.

\section{Direct Immunofluorescence Staining for Flow Cytometry [Fluorescence-Activated Cell Sorting (FACS)]}

To identify circulating monocytes and neutrophils, samples obtained by peripheral venous puncture, and the total blood was separated in $150 \mu \mathrm{l}$. Red blood cells were lysed using ammoniumchloride-potassium lysing buffer (ACK; ThermoFisher Scientific, Waltham, MA, USA) for $5 \mathrm{~min}$ at room temperature (RT), then washed and centrifuged. The pellet was resuspended in PBS-2\% fetal bovine serum, and cells were counted using TC20 (Biorad, Hercules, CA, USA). To analyze monocytes and neutrophils, flow cytometry exclusion gating strategy was used as previously described (16). Briefly, the staining cells were selected using forward and side scatter characteristics and deleting the doublets (FSC vs. SSC). Monocytes were identified using the following antibodies: CD14-PeCy7, CD16-APC, CD3-Pe, CD19-Pe, CD66b-PerCpCy5.5, CD56-APC-Cy7 
TABLE 1 | Clinical and demographic characteristics of patients with lupus nephritis (LN) who donated blood samples.

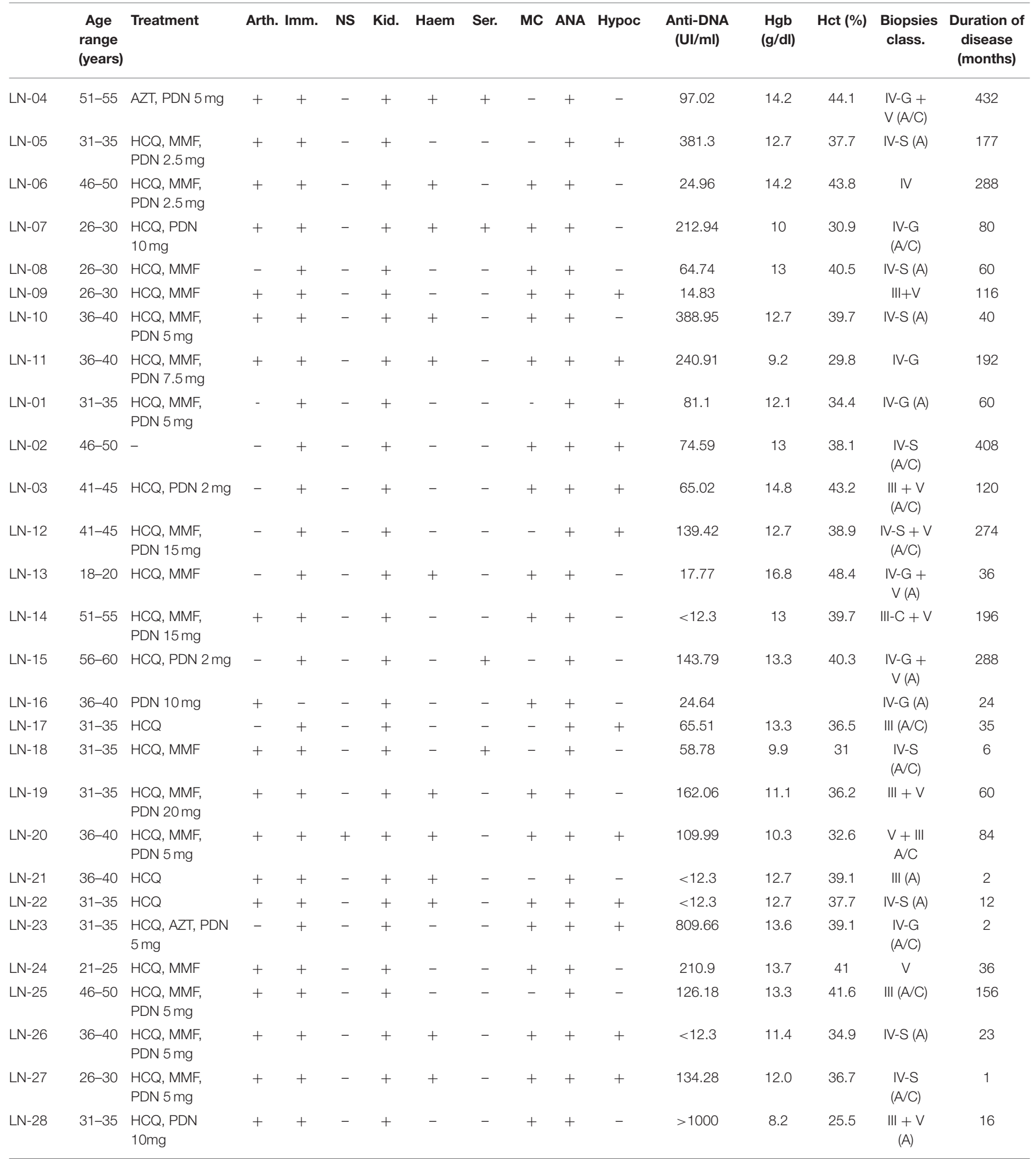

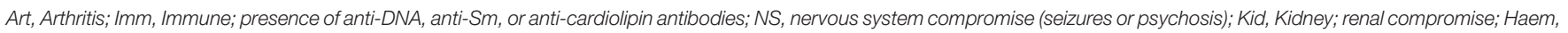

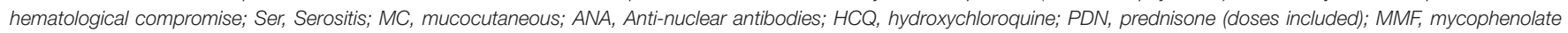

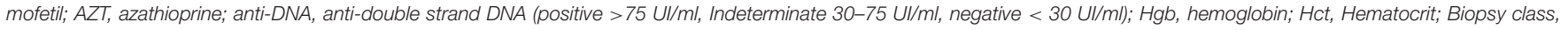
LN type III, IV, and/or $V$ as per the ISN/RPS classification. 
TABLE 2 | Demographic details of lupus nephritis (LN) patients and healthy controls recruited to obtain blood samples.

\begin{tabular}{llc}
\hline & LN patients & Healthy control \\
\hline Number & 15 & 15 \\
Gender (\% Female) & 86.7 & 86.7 \\
Age (years) \pm SD & $39.7 \pm 11.4$ & $38.11 \pm 11.22$ \\
Arthritis (\%) & 53.3 & $\mathrm{~N} / \mathrm{A}$ \\
Immune (\%) & 100 & $\mathrm{~N} / \mathrm{A}$ \\
NS (\%) & 0 & $\mathrm{~N} / \mathrm{A}$ \\
Kidney (\%) & 100 & $\mathrm{~N} / \mathrm{A}$ \\
Haem. (\%) & 40.0 & $\mathrm{~N} / \mathrm{A}$ \\
Serositis (\%) & 20.0 & $\mathrm{~N} / \mathrm{A}$ \\
MC (\%) & 72.72 & $\mathrm{~N} / \mathrm{A}$ \\
ANA (\%) & 100 & $\mathrm{~N} / \mathrm{A}$ \\
Hypocomplementemia (\%) & 46.7 & $\mathrm{~N} / \mathrm{A}$ \\
Anti-dsDNA (\%) & 54.54 & $\mathrm{~N} / \mathrm{A}$ \\
\hline
\end{tabular}

Immune, presence of anti-DNA, anti-Sm, or anti-cardiolipin antibodies; NS, nervous system compromise (seizures or psychosis); Kidney, renal compromise; Haem., hematological compromise; MC, mucocutaneous; ANA, Anti-nuclear antibodies; N/A, not applicable.

TABLE 3 | Pathological characteristics of lupus nephritis (LN) renal biopsies.

\begin{tabular}{ll}
\hline & LN patients \\
\hline Class III (number/\%) & $8(40 \%)$ \\
Class IV (number/\%) & $11(55 \%)$ \\
Class V (number/\%) & $1(5 \%)$ \\
Mean activity index score $\pm S D$ & $9.22 \pm 4.5$ \\
Mean chronicity index score $\pm S D$ & $1.17 \pm 1.2$ \\
\hline
\end{tabular}

Twenty renal biopsies with type III, IV, and/or V LN ISN/RPS classification, performed between January 2006 and January 2017 were used.

(Biolegend, San Diego, CA, USA). Neutrophils were identified using the following antibodies: CD15-APC-Fire750, CD66bPerCp, CD11b-PE, CD3-FITC, CD19-FITC, CD14-PeCy-7, HLA-DR-APC (Biolegend).

To obtain purified monocytes, peripheral blood mononuclear cells (PBMCs) were isolated by density gradient centrifugation using Ficoll-Paque (GE Healthcare, Chicago, IL, USA) as previously described (22). Then monocytes were purified using Pan Monocyte Isolation Kit, Human (Miltenyi Biotec $\left.{ }^{(}\right)$, Bergisch Gladbach) according to manufacturer's instructions. To identify monocytes, the purified cells $\left(5 \times 10^{5}\right.$ cells) were stained with the following fluorescent conjugated antibodies (Biolegend): CD14PeCy7 and CD16-APC.

For intracellular detection of $\mathrm{HO}-1$, cells were fixed with fixation/permeabilization solution kit (BD Biosciences, Franklin Lakes, NJ, USA) and stained with an unconjugated rabbit polyclonal antibody (Abcam, Cambridge, MA, USA). After $30 \mathrm{~min}$, cells were incubated with a conjugated secondary antibody (Alexa Fluor 555 or 488; ThermoFisher
Scientific). All samples were analyzed in FACS Canto II using FACSDiva software.

\section{Phagocytosis Assay}

To determine the phagocytic function of monocytes, FluoSpheres $^{\text {TM }} \quad$ Carboxylate-Modified Microspheres (ThermoFisher Scientific) were used (23). The FluoSpheres ${ }^{\mathrm{TM}}$ were incubated with $100 \mu \mathrm{g}$ of purified immunoglobulin G (IgG) for $30 \mathrm{~min}$ at $37^{\circ} \mathrm{C}$ to opsonize the beads. IgGs were purified from serum of a patient with $\mathrm{LN}$ who has high titers of anti-DNA antibodies (Table 1, LN-23) or of an HC matched in sex and age with the patient. Purified monocytes from LN patients (Table 1, LN-1-LN-15) or from HC (Table 2) were adjusted to $5 \times 10^{5}$ cells and were incubated with opsonized FluoSpheres ${ }^{\mathrm{TM}}$ (ratio of monocytes to beads $=1: 5$ ) for $1 \mathrm{~h}$ at $37^{\circ} \mathrm{C}$ to determine the phagocytic function or at $4^{\circ} \mathrm{C}$ to detect nonspecific binding. Monocytes were washed three times using $1 \mathrm{ml}$ of complete PBS and analyzed in LSRFortessa X20 Flow Cytometer using FACSDiva software (BD Immunocytometry Systems, San Jose, CA, USA).

\section{Determination of Reactive Oxygen Species (ROS)}

ROS production was determined in $5 \times 10^{5}$ purified monocytes using CellROX ${ }^{\mathrm{TM}}$ Green Flow Cytometry Assay Kit (ThermoFisher Scientific) according to manufacturer's instructions. Briefly, monocytes were incubated with $250 \mu \mathrm{M}$ of CellROX ${ }^{\circledR}$ reagent for $30 \mathrm{~min}$ at $37^{\circ} \mathrm{C}$ in the dark. To obtain a positive and a negative control for ROS production, monocytes were preincubated with tert-butyl hydroperoxide (TBHP, $250 \mu \mathrm{M})$ or N-acetylcysteine (NAC, $1 \mathrm{mM}$ ), respectively, for $1 \mathrm{~h}$ at $37^{\circ} \mathrm{C}$ before incubation with CellROX ${ }^{\circledR}$. During the final 15 min of staining, SYTOX ${ }^{\circledR}$ Red Dead Cell stain solution was added $(5 \mu \mathrm{M})$ in each sample and mixed gently. Samples were immediately analyzed by flow cytometry.

\section{Induction of HO-1 Using Cobalt Protoporphyrin (CoPP)}

Before phagocytosis and/or ROS determination assays, purified monocytes $\left(5 \times 10^{5}\right)$ were treated with $100 \mu \mathrm{M}$ of $\mathrm{CoPP}$ (Frontier Scientific, Logan, UT, USA) for $2 \mathrm{~h}$ at $37^{\circ} \mathrm{C}$ to induce HO-1 expression. Alternatively, to inhibit HO-1 expression, monocytes were treated with $100 \mu \mathrm{M}$ of tin protoporphyrin (SnPP; Frontier Scientific) using the same protocol as for CoPP treatment. After $2 \mathrm{~h}$, purified monocytes were washed and used for different experiments. CoPP and $\mathrm{SnPP}$ were dissolved in $0.1 \mathrm{M} \mathrm{NaOH}$ to prepare a stock solution of $10 \mathrm{mM}$.

\section{Immunohistochemistry}

Tissues were deparaffinized in xylene and rehydrated using ethanol. The activity of endogenous peroxidase was blocked. For immunohistochemistry staining, immunoperoxidase system (VECTASTAIN PK-6200; Vectors laboratories, Burlingame, CA, USA) was used. Samples were stained with a mouse antiHO1 (Abcam, Cambridge, MA, USA) monoclonal antibody and 
A
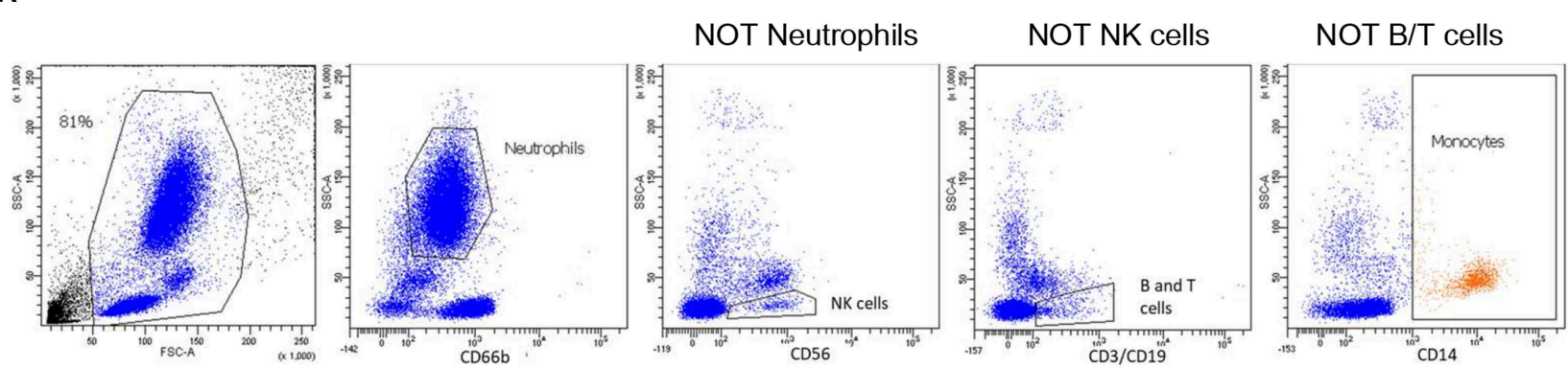

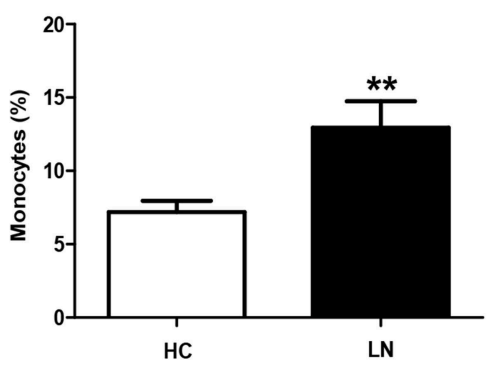

E

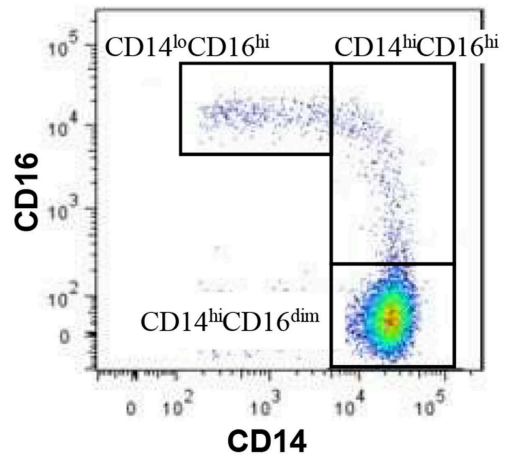

H

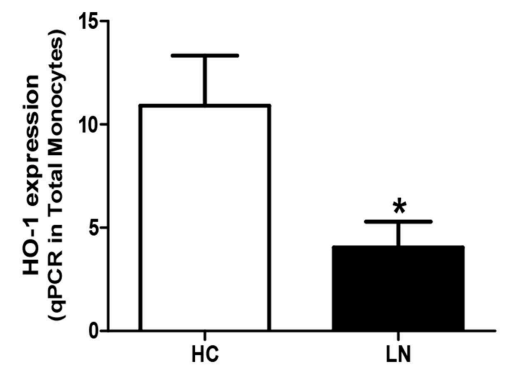

C

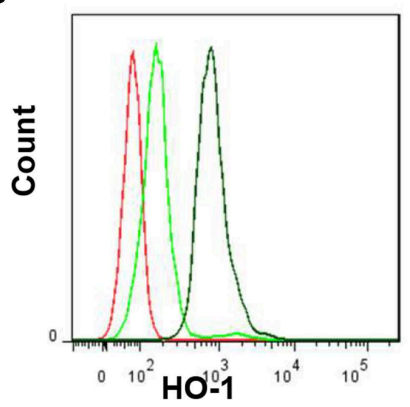

F

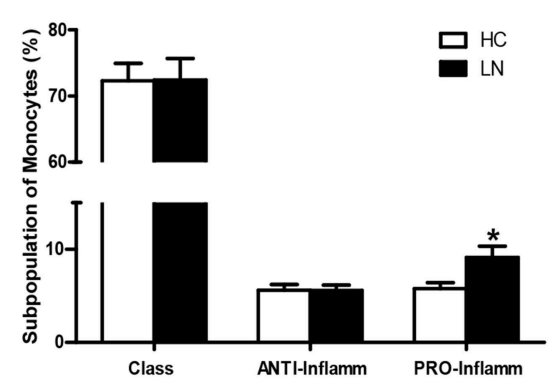

I

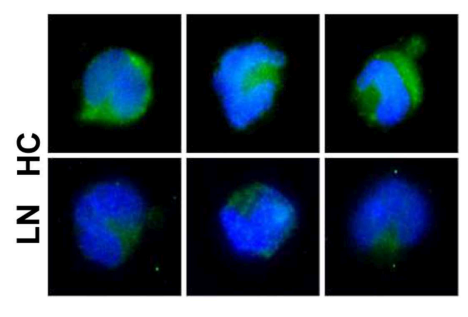

D

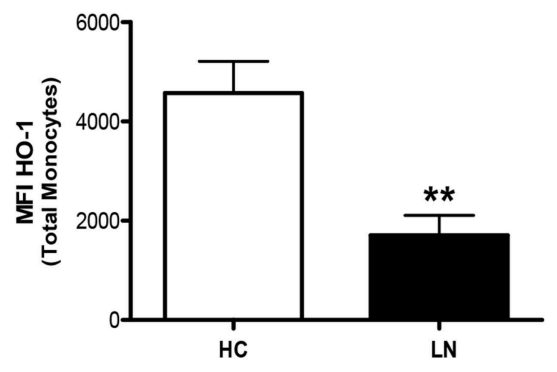

G

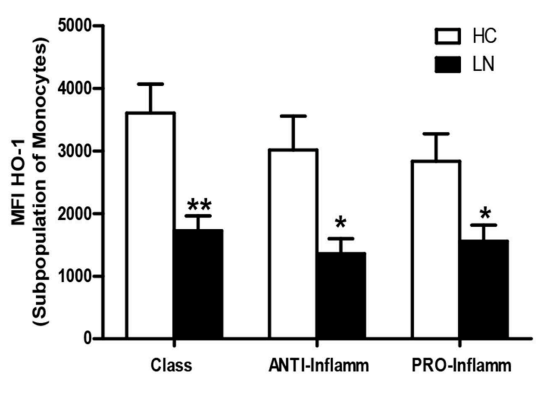

J

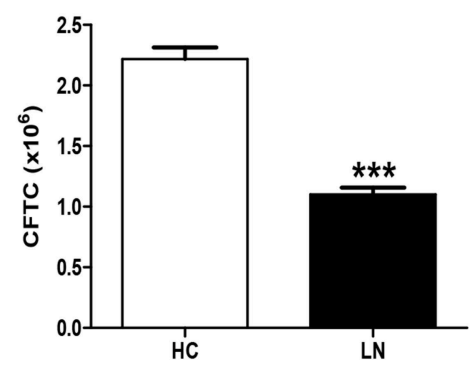

FIGURE 1 | Monocytes from peripheral blood of lupus nephritis (LN) patients express lower levels of heme oxygenase (HO)-1 than healthy controls (HC). The proportion of cells and HO-1 expression [mean fluorescence intensity (MFI)] were determined in peripheral blood using flow cytometry. (A) Gating strategy for identification of monocytes showing successive exclusion of neutrophils, natural killer (NK) cells, and B and T cells. (B) Percentage of monocytes circulating. (C) Representative histograms for $\mathrm{HO}-1$ expression in monocytes of LN patients and HC. Red: autofluorescence; light green: $L N$ monocytes; green: HC monocytes. (D) MFI value of HO-1 expression. (E) Representative dot plot to identify the different subpopulations of monocytes. (F) Percentage of each subset's monocytes. (G) Representative MFI value of HO-1 expression in each subset of monocytes. (H) HO-1 expression was quantified in purified monocytes by real-time RT-PCR. (I) Immunofluorescence of HO-1 in purified monocytes. (J) Quantification of HO-1 expression [corrected total cell fluorescence (CTCF)] in purified monocytes. Graphs are showing the mean \pm standard deviation. $n=15 \mathrm{LN}$ patients (black bars) and $n=15 \mathrm{HC}$ (white bars). ${ }^{\star} P<0.05,{ }^{* \star} P<0.01$, ${ }^{\star \star \star} P<0.001$ by Mann-Whitney test. 


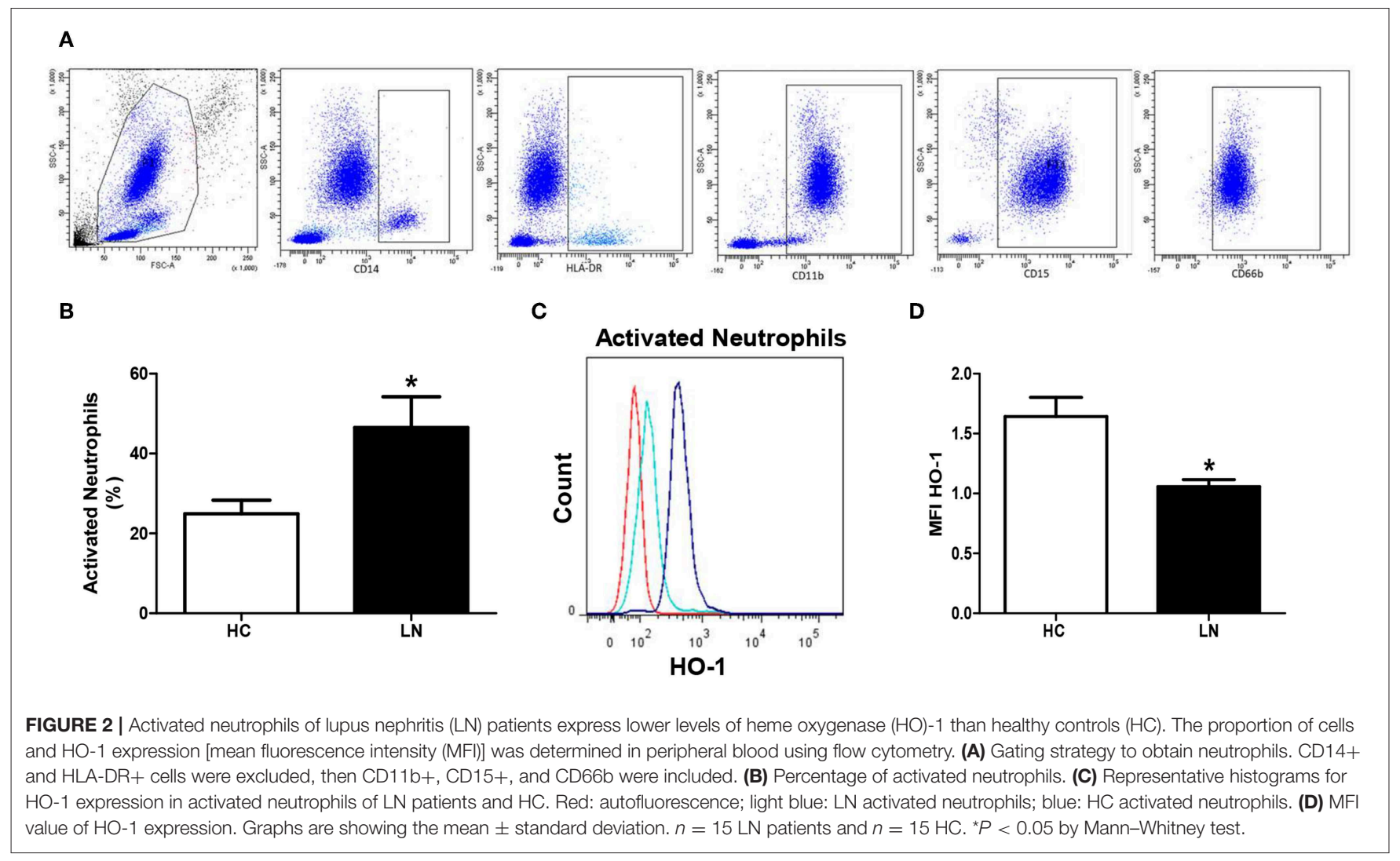

analyzed using ImmPACT ${ }^{\mathrm{TM}}$ AEC (SK-4205). Finally, samples were counterstained with hematoxylin and blindly evaluated by a pathologist (GM, AV) who determined the $\mathrm{H}$ - Score, which includes intensity (0-negative, 1 -weak, 2 -moderate, and 3strong) and the percentage of cells that were positive for $\mathrm{HO}-1$ staining (24).

\section{Immunofluorescence in Renal Biopsies}

Biopsies were deparaffinized, rehydrated, and stained overnight with conjugated antibodies to identify monocytes (CD14; Abcam), activated neutrophils (CD66b; Biolegend), and macrophages (CD68; ThermoFisher Scientific), together with an unconjugated mouse/rabbit anti-HO-1 monoclonal antibody (Abcam). A secondary conjugated antibody (antimouse Alexa Fluor 555 and anti-rabbit Alexa Fluor 488; ThermoFisher Scientific) was also used. For nuclei staining, samples were incubated with DAPI (ThermoFisher Scientific). Images were analyzed using ImageJ software (NIH, Bethesda, $\mathrm{MD}$, USA) to calculate the corrected total cell fluorescence (CTCF) (25).

\section{RNA Extraction and qPCR}

Total RNA was extracted from monocytes using TRIzol (ThermoFisher Scientific), and cDNAs were generated from $1 \mu \mathrm{g}$ RNA using ImProm-II ${ }^{\mathrm{TM}}$ Reverse Transcription System (Promega, Fitchburg, WI, USA) according to the manufacturer's protocol. cDNA products were used as template for $\mathrm{qPCR}$ experiments performed in a StepOnePlus ${ }^{\mathrm{TM}}$ RealTime PCR system (Applied Biosystems) using Fast SYBR ${ }^{\circledR}$ Green Master Mix (Applied Biosystems). Relative expression of HO-1 was calculated through the $\Delta \Delta \mathrm{Ct}$ method using glyceraldehyde 3-phosphate dehydrogenase (GAPDH) and $18 \mathrm{~S}$ genes as reference. Amplification was carried out with $160 \mathrm{nM}$ of the following primers $\left(5^{\prime} \rightarrow 3^{\prime}\right)$ : HO-1: forward (fw): CCCCAACGAAAAGCACATCC—reverse (rv): AGACAG CTGCCACATTAGGG; GAPDH: fw: GGTGGTCTCCT CTGACTTCAACA—rv: GTTGCTGTAGCCAAATTCGTTGT; 18S: fw GTA ACC CGT TGA ACC CCA TT-rv: CCA TCC AAT CGG TAG TAG CG. Efficiencies were 98.96\% (HO-1), $101.8 \%$ (GAPDH), and $103.9 \%$ (18S). $\Delta \Delta \mathrm{Ct}$ was defined as $(\Delta \mathrm{Ct}$ GOI treatment $-\Delta \mathrm{Ct}$ GOI control) ( $\Delta \mathrm{Ct}$ reference treatment $-\Delta \mathrm{Ct}$ reference control) and was calculated automatically by StepOne Software v2.3 (Applied Biosystems).

\section{Statistical Analysis}

The results of all groups were expressed as mean \pm SD. Statistical analyses were performed with GraphPad Prism 5 software (La Jolla, CA, USA) or SPSS-17 statistical software (SPSS Inc., Chicago, IL, USA). Mann-Whitney non-parametric test was used to compare LN patients with control groups. For statistical analysis between treatments, paired one-way Friedman test was used with Bonferroni post-hoc test over the ranked data. $P<0.05$ were considered significant. 


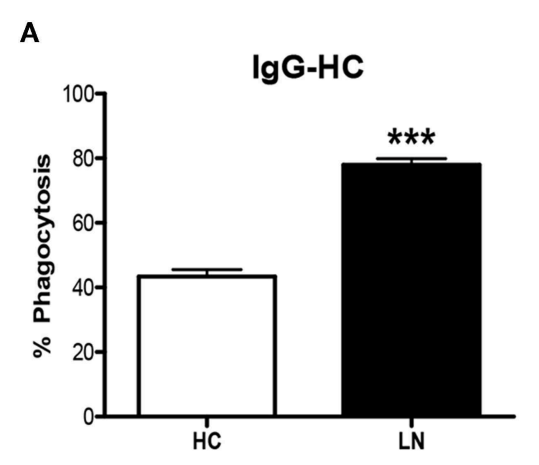

C

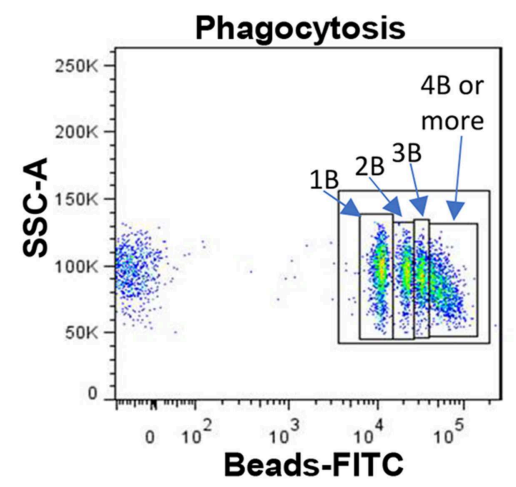

B

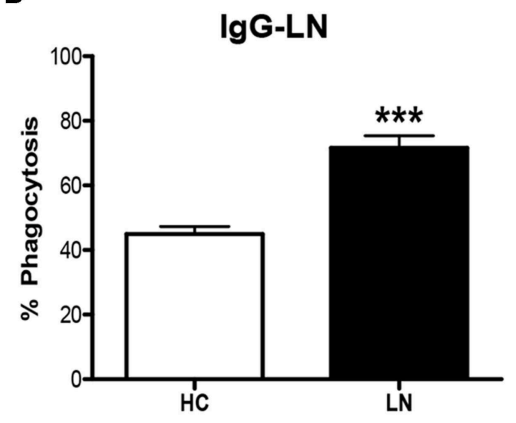

D

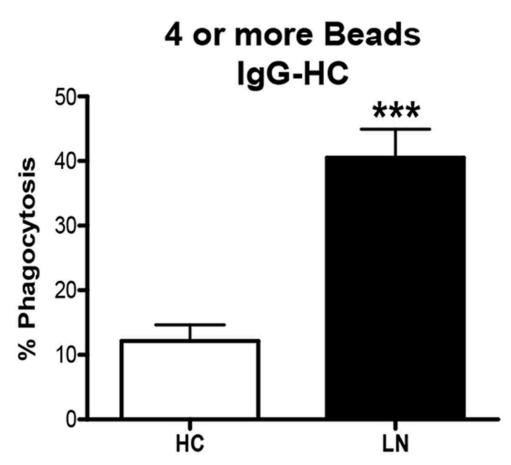

E

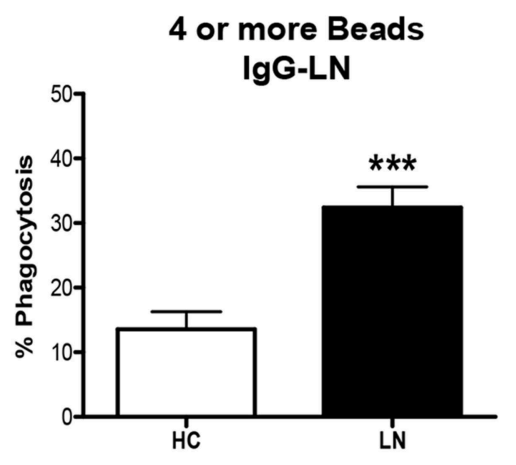

FIGURE 3 | Monocytes of lupus nephritis (LN) patients show increased phagocytic activity compared with those of healthy controls (HC). (A,B) Phagocytic activity of purified monocytes incubated with opsonized beads using lgG from HC (lgG-HC) or LN patient (IgG-LN). (C) Representative dot plot to identify monocytes phagocyting different numbers of beads. (D,E) Percentage of monocytes that phagocyte four or more beads opsonized with lgG-HC or lgG-LN. Graphs are showing the mean \pm standard deviation. $n=15 \mathrm{LN}$ patients and $n=15 \mathrm{HC}$. ${ }^{\star \star \star} P<0.001$ by Mann-Whitney test.

\section{RESULTS}

\section{Pro-Inflammatory Monocytes and Activated Neutrophils of LN Patients Show Lower Expression of HO-1 Than Those of HC}

The expression of HO-1 in peripheral monocytes and neutrophils was evaluated in whole blood of LN patients (Table 1; patients LN-1-LN-15) and HC (Table 2; $n=15$ ). To evaluate monocytes in peripheral blood, neutrophils and lymphocytes were excluded (Figure 1A). LN patients have higher percentage of monocytes than that of HC (Figure 1B). Interestingly, these LN monocytes had lower protein levels of $\mathrm{HO}-1$ than those of HC monocytes (Figures 1C,D). Moreover, recent studies have revealed that peripheral monocytes can be divided based on the level of expression of type IIIa FC $\gamma$ receptor (CD16) $(17,26)$, in classical $\left(\mathrm{CD} 14^{\text {hi }} \mathrm{CD} 16^{\mathrm{lo}}\right)$, anti-inflammatory (intermediate, $\left.\mathrm{CD} 14^{\mathrm{hi}} \mathrm{CD} 16^{\mathrm{hi}}\right)$, and pro-inflammatory monocytes (nonclassical, $\mathrm{CD} 14^{\mathrm{lo}} \mathrm{CD} 16^{\mathrm{hi}}$ ) (Figure 1E). Interestingly, a significant increase of proinflammatory monocytes was observed in LN patients when compared with $\mathrm{HC}$; however, no significant differences were observed when classical and anti-inflammatory monocytes were evaluated in both groups (Figure 1F). HO-1 expression was decreased in all subsets of monocytes, including pro-inflammatory monocytes (Figure 1G). In addition, we analyzed HO-1 expression using MACS kit by real-time PCR (qPCR) (Figure 1H) and immunofluorescence (Figures 1I,J) in purified monocytes of $\mathrm{LN}$ patients and $\mathrm{HC}$. We confirmed that HO-1 levels were decreased in LN monocytes compared with those of $\mathrm{HC}$.

To evaluate HO-1 expression in peripheral neutrophils, cells $\mathrm{CD}_{11} \mathrm{~b}^{+} / \mathrm{CD} 15^{+}$were identified using exclusion strategy. After deletion of doublets cells from FSC vs. SSC plot, monocytes and lymphocytes were identified and excluded (Figure 2A). No significant differences between LN patients and HC were found in HO-1 expression in peripheral neutrophils $(p=0.5772)$. However, two different subsets of neutrophils based on the expression of CD66b have been described; thus, $\mathrm{CD} 6 \mathrm{~b}^{+}$cells are activated neutrophils (27). Remarkably, LN patients showed higher percentage of circulating activated neutrophils than $\mathrm{HC}$ (Figure 2B), and when HO-1 expression was evaluated in this population, LN-activated neutrophils presented lower levels of this enzyme than HC (Figures 2C,D). 


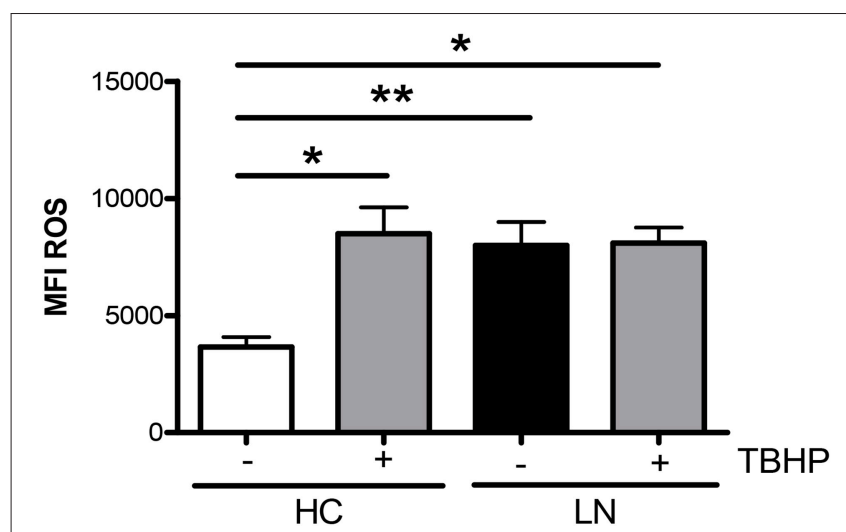

FIGURE 4 | Reactive oxygen species (ROS) levels are elevated in monocytes of lupus nephritis ( $L N$ ) patients. ROS mean intensity of fluorescence (MFI) levels were determined by fluorescence-activated cell sorting (FACS) by using CellROX ${ }^{\circledR}$ Green Reagent. TBHP is a ROS inducer and was used as a positive control. Graphs are showing the mean \pm standard deviation. $n=15$ LN patients and $n=15$ healthy controls $(\mathrm{HC}) .{ }^{*} P<0.05$ by Wilcoxon matched-pairs signed rank test $( \pm \mathrm{TBHP}) .{ }^{\star} P<0.05$, ${ }^{* \star} P<0.01$ by Mann-Whitney test (between groups).

\section{Monocytes of LN Patients Have Different Phagocytic Capabilities Than Monocytes of $\mathrm{HC}$}

An important function of monocytes is the phagocytosis of antibody-coated microbes and cellular debris. As a way to evaluate this function, we investigated the ability of purified LN and HC monocytes to phagocytose IgG-opsonized beads. The phagocytic ability was measured by FACS, and the total phagocytosis was calculated as the percentage of cells with engulfed beads. We detected significant differences in the capacity of monocytes to engulf IgG-opsonized beads when comparing monocytes of LN patients with those of HC (Figures 3A,B). Surprisingly, the phagocytosis level was increased in monocytes of LN patients compared with HC, independently of whether the IgGs used to opsonize the beads came from an LN patient or a HC. Therefore, trying to further understand our unpredictable results, we turned our focus to the analysis of the percentage of monocytes that phagocyte different number of beads (Figure 3C). Interestingly, the most important difference was observed in the percentage of monocytes that phagocyte four or more beads, which is higher in LN monocytes regardless of the IgGs used to opsonize the beads (Figures 3D,E). Based on these results, we decided to evaluate ROS production as an additional approach to assess the effector function of monocytes, since it is widely known that ROS production is part of the mechanisms used by monocytes to remove microbes and other threats. Noteworthy, ROS levels at baseline were higher in monocytes of LN patients than in those of HC. Moreover, LN monocytes show at baseline similar levels of ROS to those achieved when HC monocytes were treated with TBHP, a potent ROS inducer (Figure 4).

\section{HO-1 Induction Improves the Phagocytic Activity and Decreases ROS Production of LN Monocytes}

To evaluate whether increasing the expression of HO-1 modulates ROS production, we treated purified monocytes of LN patients and $\mathrm{HC}$ with CoPP, which is known to promote the expression and activity of HO-1 $(28,29)$. In addition, to inhibit HO-1 induction, SnPP was used as a control (30). We first determined the appropriate concentration of CoPP that would achieve the maximum level of HO-1 induction without compromising cellular viability (Figure 5A). The expression of HO-1 was assessed by qPCR and flow cytometry. As shown in Figures 5B,C, purified monocytes upregulate the expression of HO-1 in response to CoPP. Interestingly, unlike the results previously shown, when monocytes were treated with CoPP, the percentage of LN monocytes that phagocyte IgG-beads decreased regardless of whether the IgG came from HC or LN patient, reaching similar values between LN patients and HC (Figure 6A). In addition, the phagocytic activity of $\mathrm{HC}$ monocytes did not change with CoPP treatment. Furthermore, with CoPP treatment, we did not observe differences in the percentage of monocytes that phagocyte four or more beads (Figure 6B), indicating that the induction of HO-1 regulates phagocytosis in monocytes of LN patients. On the other hand, to assess the function of LN monocytes in response to the induction of HO-1 in $\mathrm{LN}$ patients, we evaluated ROS production in cells treated with CoPP. Interestingly, HO-1 induction results in a decrease of ROS production in LN and HC (Figure 6C), leading the monocytes of LN patients and the monocytes of HC to produce similar levels of ROS. Noteworthy, these results, including the effect of CoPP in total phagocytosis, phagocytosis of four or more beads, and ROS production, were reversed when treating monocytes with SnPP, an inhibitor of HO-1 (Figure 6). Even in some cases, as in phagocytosis, $\mathrm{HC}$ monocytes treated with SnPP phagocytosed even more beads than untreated monocytes from HC (Figure 6).

\section{HO-1 Is Expressed in Renal Tubular Epithelial Cells and Infiltrating Innate Immune Cells of LN Patients}

HO-1 expression was evaluated in renal biopsies of LN patients (Table 1; patients LN-09-LN-28; $n=20$ ) and HC (Table 4; $n=3$ ) using immunohistochemistry. Since obtaining renal tissue from $\mathrm{HC}$ is extremely difficult, we were able to evaluate HO-1 expression in only three biopsies of subjects who underwent surgery, and a nephrectomy had to be performed as part of the surgical protocol for different reasons, but their kidneys were healthy (HC). Interestingly, we observed that HO-1 was mostly expressed in the cytoplasm of renal tubular epithelial cells (RTEC), whereas other regions of the kidney such as the glomeruli showed limited expression (Figure 7A). Nevertheless, HO-1 expression was significantly higher in HC biopsies than in that in $\mathrm{LN}(173.33 \pm 6.67$ vs. $82.45 \pm$ 12.70, $p=0.0313$; Figure 7B). However, numbers are small, and although promising, further studies are needed to make definitive conclusions. Therefore, we decided to explore HO1 expression in healthy tissue of biopsies of patients who had 
A

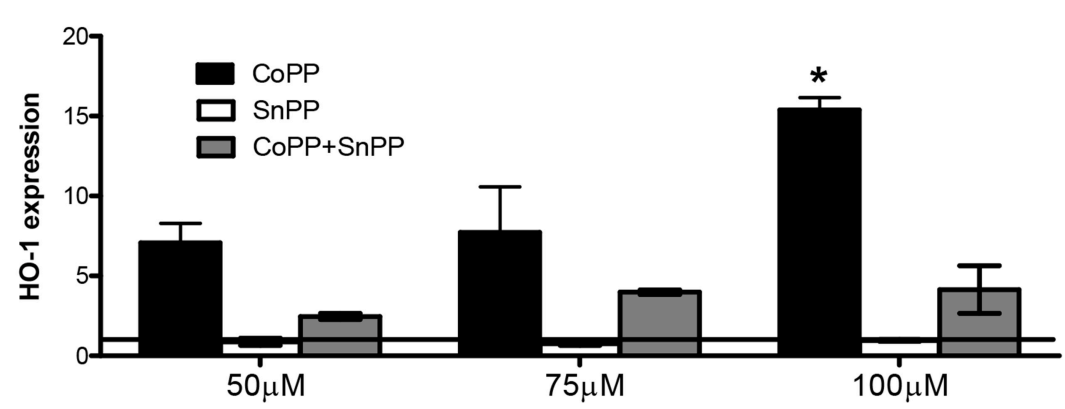

B

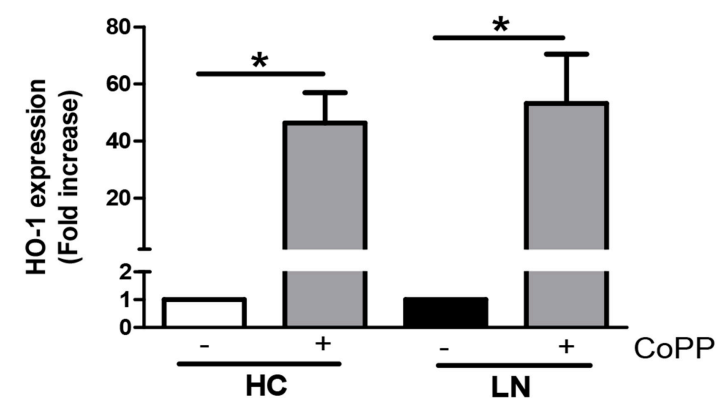

C

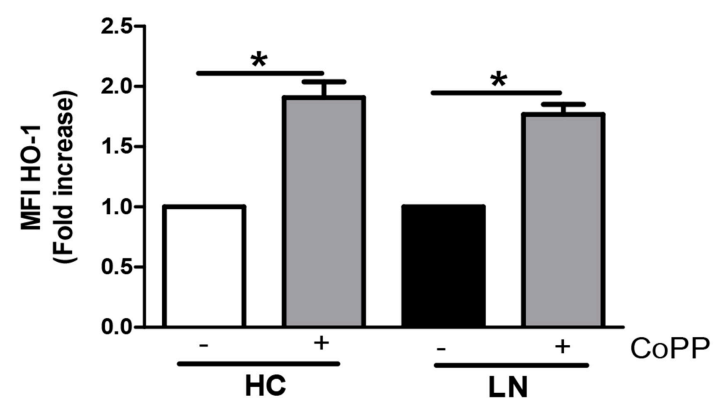

FIGURE 5 | Cobalt protoporphyrin (CoPP) but not tin protoporphyrin (SnPP) induces heme oxygenase (HO)-1 expression in purified monocytes. (A) HO-1 expression was quantified in purified monocytes from lupus nephritis (LN) patients by real-time RT-PCR with different treatments. (B,C) Purified monocytes from healthy controls $(\mathrm{HC})$ and LN patients were treated with $100 \mu \mathrm{M}$ CoPP for $2 \mathrm{~h}$ at $37^{\circ} \mathrm{C}$, and $\mathrm{HO}-1$ expression was evaluated by real-time RT-PCR (B) and fluorescence-activated cell sorting (FACS) (C). ${ }^{\star} P<0.05$; by Wilcoxon matched-pairs signed rank test $( \pm$ CoPP).

a nephrectomy due to the diagnosis of kidney cancer (CC) (see section Materials and Methods for characteristics and Table 4; $n=8$ ). In this case, HO-1 levels in LN biopsies were lower than those in CC biopsies but did not reach statistical significance ( $122.5 \pm 15.32$ vs. $82.45 \pm 12.7, p=0.0658)$. In addition, we evaluated HO-1 expression in renal biopsies of five patients with antineutrophil cytoplasmic antibodies (ANCA)associated vasculitis also by immunohistochemistry, and HO1 expression was lower than that of HC biopsies (173.33 \pm 6.67 vs. $43.70 \pm 22.33, p=0.0358$ ) but did not reach statistical significance when compared to that of LN patients (data not shown).

However, when HO-1 was evaluated in infiltrating cells of LN biopsies using immunofluorescence, we found that monocytes, macrophages, and neutrophils showed a low expression of HO-1 compared with the strong expression seen in RTEC (Figures 7C,D). Monocytes, macrophages and neutrophils were identified using specific staining for CD14, CD68, and CD66b, respectively. In addition, infiltrating cells were quantified and normalized to the total area of the biopsy. As expected, the number of infiltrating monocytes, macrophages, and neutrophils in LN biopsies was significantly higher in LN biopsies compared with CC (Figure 8). It is well-known that $\mathrm{HO}-1$ participates in inflammatory processes, increasing its expression as a regulatory mechanism. However, infiltrating cells in LN biopsies showed low levels of HO-1, as well as circulating monocytes and activated neutrophils, which could be fostering tissue damage and disease development.

\section{DISCUSSION}

Monocytes, macrophages, and neutrophils play an important role in human and murine $\operatorname{LN}(3,31,32)$. We found that innate immune cells of patients with LN show lower expression of HO-1, have impaired functions at baseline, such as increased phagocytosis of opsonized beads and increased ROS production. ROS level and phagocytosis are reduced when $\mathrm{HO}-1$ expression is induced with CoPP. The predominance of CD $14^{\text {lo }} \mathrm{CD} 16^{\text {hi }}$ subsets of monocytes could be contributing to the pro-inflammatory environment of LN (33). CD16 receptors expressed in monocytes exhibit high-affinity binding to the FC portion of polymeric IgG antibodies and immune complexes (IC). This interaction leads to activation of monocytes/macrophages and triggers several effector functions, such as phagocytosis, antibody-dependent cell-mediated cytotoxicity, release of inflammatory mediators, and clearance of IC $(18-20,33)$. In fact, it has been shown that $\mathrm{CD} 6^{+}$monocytes and activated neutrophils can exert pro-inflammatory functions secreting TNF- $\alpha$ and interferon (IFN) $-\gamma$ (32-35), which have been linked to the pathogenesis of LN $(32,36)$. Serum levels and renal production of these cytokines are increased at the onset of renal disease $(32,34-37)$, 


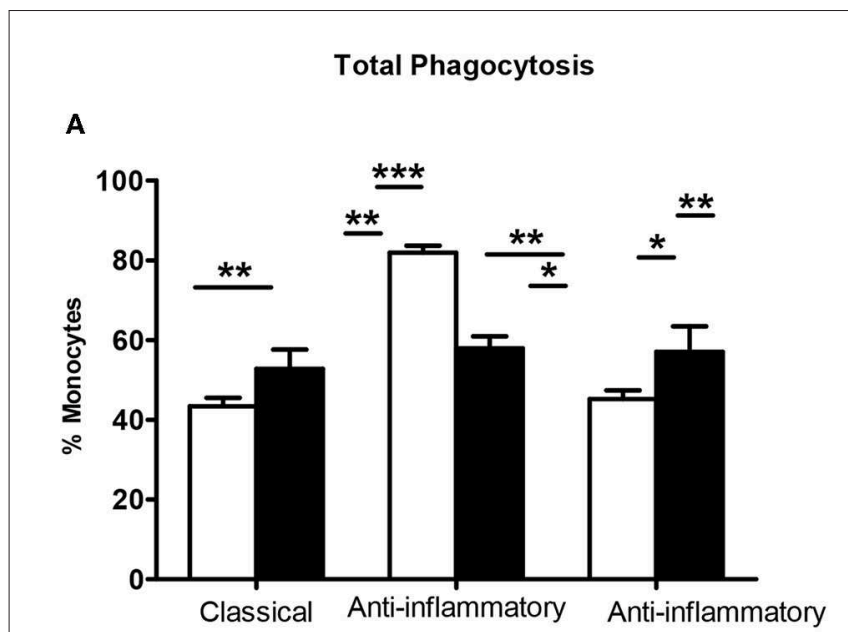

B

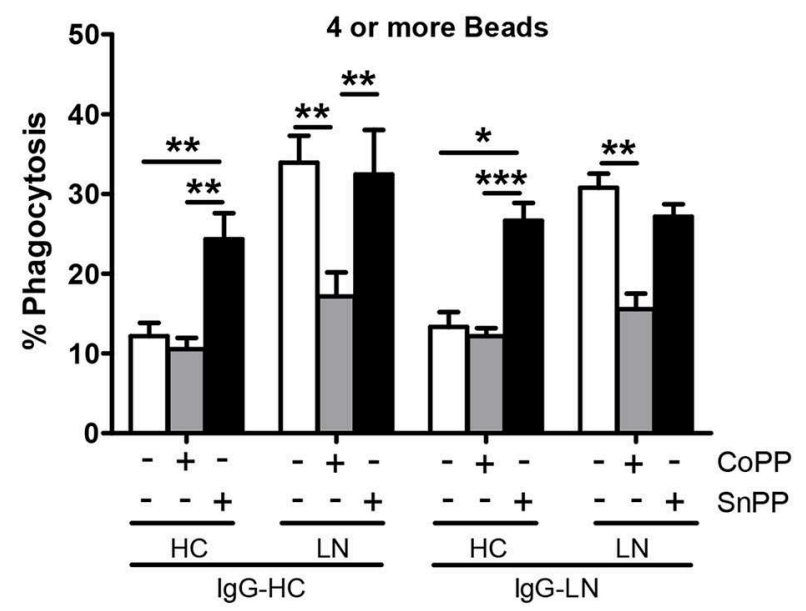

C

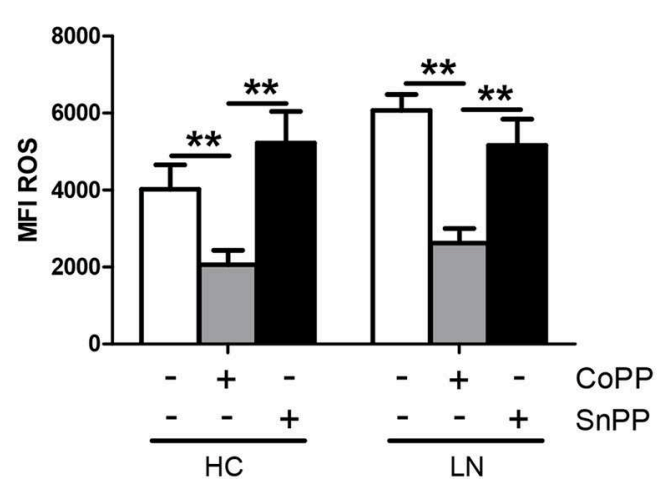

FIGURE 6 | Heme oxygenase (HO)-1 induction in lupus nephritis (LN) and healthy control $(\mathrm{HC})$ monocytes decreases phagocytic activity and reactive oxygen species (ROS) production. (A) Total phagocytic activity of purified monocytes of $\mathrm{LN}$ patients or $\mathrm{HC}$ previously treated with cobalt protoporphyrin (CoPP) or tin protoporphyrin (SnPP) to induce or inhibit HO-1 expression, respectively. (B) Percentage of monocytes treated with CoPP or SnPP that phagocyte four or more beads. (C) ROS levels in monocytes incubated with CoPP or SnPP. Graphs are showing the mean \pm standard deviation. $n=15$ LN patients and $\mathrm{n}=15 \mathrm{HC} .{ }^{\star} P<0.05,{ }^{\star \star} P<0.01,{ }^{\star \star \star} P<0.001$ by Friedman test $( \pm \mathrm{CoPP} \pm \mathrm{SnPP})$.
TABLE 4 | Demographic details of lupus nephritis (LN) patients, healthy controls, and cancer control recruited to obtain renal biopsies.

\begin{tabular}{lcll}
\hline & LN patients & $\begin{array}{l}\text { Healthy } \\
\text { control } \\
\text { (healthy } \\
\text { kidney) }\end{array}$ & $\begin{array}{l}\text { Cancer control } \\
\text { (tissue not } \\
\text { infiltrated by tumor) }\end{array}$ \\
\hline Number & 20 & 3 & 8 \\
Gender (\% Female) & 90.0 & 75.0 & 37.5 \\
Age (years) \pm SD & $37.4 \pm 10.2$ & $50.3 \pm 27.3$ & $56.6 \pm 8.4$ \\
Arthritis (\%) & 60.0 & N/A & N/A \\
Immune (\%) & 95.0 & N/A & N/A \\
NS (\%) & 20.0 & N/A & N/A \\
Kidney (\%) & 100 & N/A & N/A \\
Haem. (\%) & 35.0 & N/A & N/A \\
Serositis (\%) & 10.0 & N/A & N/A \\
MC (\%) & 65.0 & N/A & N/A \\
ANA (\%) & 100 & N/A & N/A \\
Hypocomplementemia (\%) & 50.0 & N/A & N/A \\
Anti-dsDNA (\%) & 50.0 & N/A & N/A \\
\hline & & & \\
\hline
\end{tabular}

Immune, presence of anti-DNA, anti-Sm, or anti-cardiolipin antibodies; NS, nervous system compromise (seizures or psychosis); Kidney, renal compromise; Haem., hematological compromise; MC, mucocutaneous; ANA, Anti-nuclear antibodies; N/A, not applicable.

and it has been described in murine models that the use of blocking antibodies against IFN- $\gamma$ causes a significant delay in disease, stabilizing glomerulonephritis, and significantly decreasing proteinuria, which is associated with improvement in survival $(36,37)$.

Interestingly, $\mathrm{HO}-1$ has an anti-inflammatory role in immune cells with inhibition of pro-inflammatory signals and recovery of cell homeostasis (38). Various studies have shown that inflamed tissues upregulate the expression of $\mathrm{HO}-1$, which has been proved in gastric ulcers, inflammatory bowel disease, colitis, enteritis, and other diseases (39). The data presented here support that the low expression of HO-1 in monocytes and potentially neutrophils might play an active and relevant role in the pathogenesis of LN, similar to what was observed in multiple sclerosis (MS) (40).

The mechanism responsible for the anti-inflammatory properties of HO-1 is not fully known. However, extensive evidences have demonstrated that the beneficial effects of HO1 is mediated via the breakdown of heme, a vigorous pro-oxidant molecule and a noxious stimulus that amplifies oxidative insult in several models of injury, and the generation of protective products as carbon monoxide (CO), biliverdin with the subsequent formation of bilirubin, and ferritin via iron release from the heme moiety $(41,42)$ (Figure 9). On the other hand, has been described that monocyte HO-1 inhibits protease, nitric oxide and pro-inflammatory cytokine production, immune cell recruitment and infiltration $(8,43)$; induces anti-inflammatory interferon-beta; and inhibits cell chemoattraction $(40,44)$ by downregulation of chemokine receptor $(45,46)$. Furthermore, HO-1 may be an important effector of Foxp3-mediated immune suppression (8).

Disturbances in the phagocytosis of apoptotic cells have been proposed to play a role in the development of autoimmunity, 
A

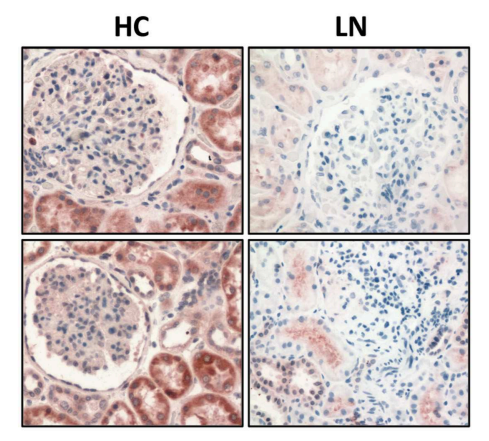

C
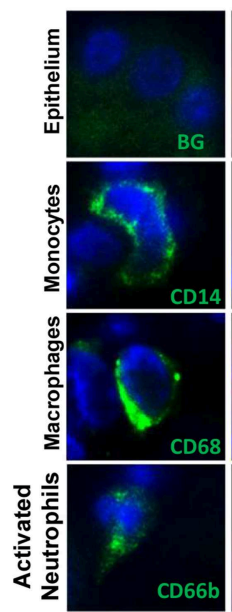

B

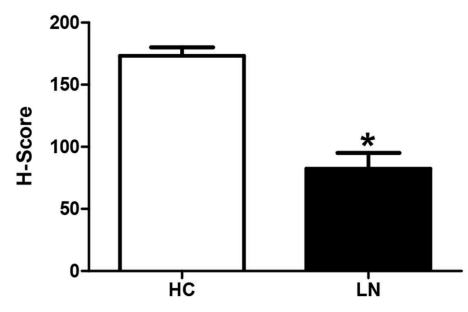

D

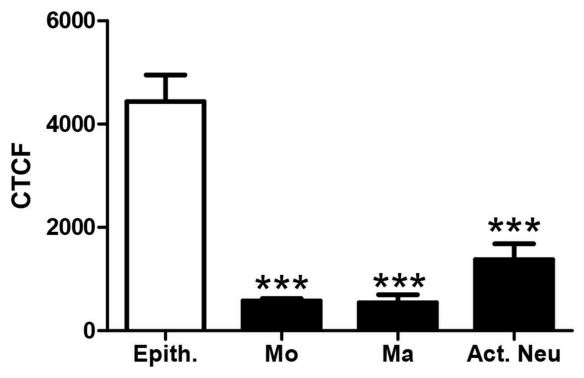

FIGURE 7 | Heme oxygease (HO)-1 expression is lower in infiltrating immune cells than in renal tubular epithelial cells (RTEC) of lupus nephritis (LN) patients. Renal biopsies from $L N$ patients and healthy controls $(\mathrm{HC})$ were analyzed to quantify HO-1 expression. (A) Representative images of immunohistochemistry of $L N$ and $\mathrm{HC}$ biopsies. (B) Quantification of $\mathrm{H}$-score in LN and HC kidney biopsies. (C) Representative images of HO-1 expression in renal tubular epithelial cells (RTEC, epithelium) and infiltrating cells (monocytes, macrophages, and activated neutrophils) in LN biopsies detected by immunofluorescence (IF). (D) Quantification of HO-1 expression [corrected total cell fluorescence (CTCF)] in epithelium (Epith) and immune cells (Mo, monocytes; Ma, macrophages; Act. Neu, activated neutrophils). Graphs are showing the mean \pm standard deviation. $n=20$ LN biopsies and $n=3$ HC. ${ }^{*} P<0.05,{ }^{\star \star \star} P<0.001$ by Mann-Whitney test $(\mathbf{A}-\mathbf{C})$. ${ }^{\star \star \star} P<0.001$ by Wilcoxon matched-pairs signed rank test (D).

A

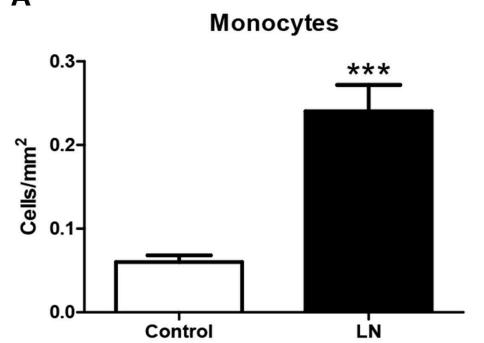

B

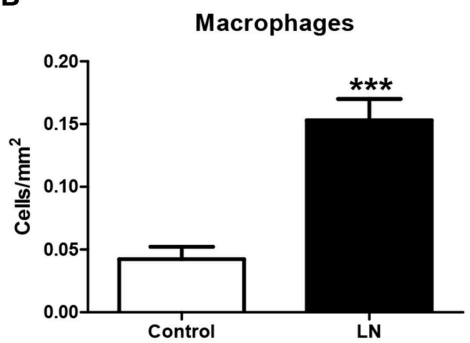

C

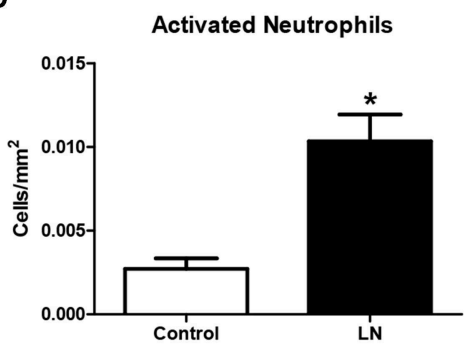

FIGURE 8 | Lupus nephritis (LN) biopsies show higher number of infiltrating cells than cancer controls (CC). Renal biopsies from LN patients and CC were analyzed to identify infiltrating immune cells by immunofluorescence (IF). Infiltrating monocytes (A), macrophages (B), and activated neutrophils (C) were quantified and normalized per square millimeter. Graphs are showing the mean \pm standard deviation. $n=20$ LN biopsies and $n=8$ CC. ${ }^{\star} P<0.05$, ${ }^{\star \star \star} P<0.001$ by Mann-Whitney test.

especially in SLE (47-50). Previous works have described defects in the clearance of apoptotic cells in lupus mice and patients $(51,52)$. In contrast to these reports, our data show an increment in the phagocytosis of monocytes of LN patients. This difference could be explained because most of the published data have evaluated phagocytosis of macrophages that have 


\section{Cellular Stress and Damage}

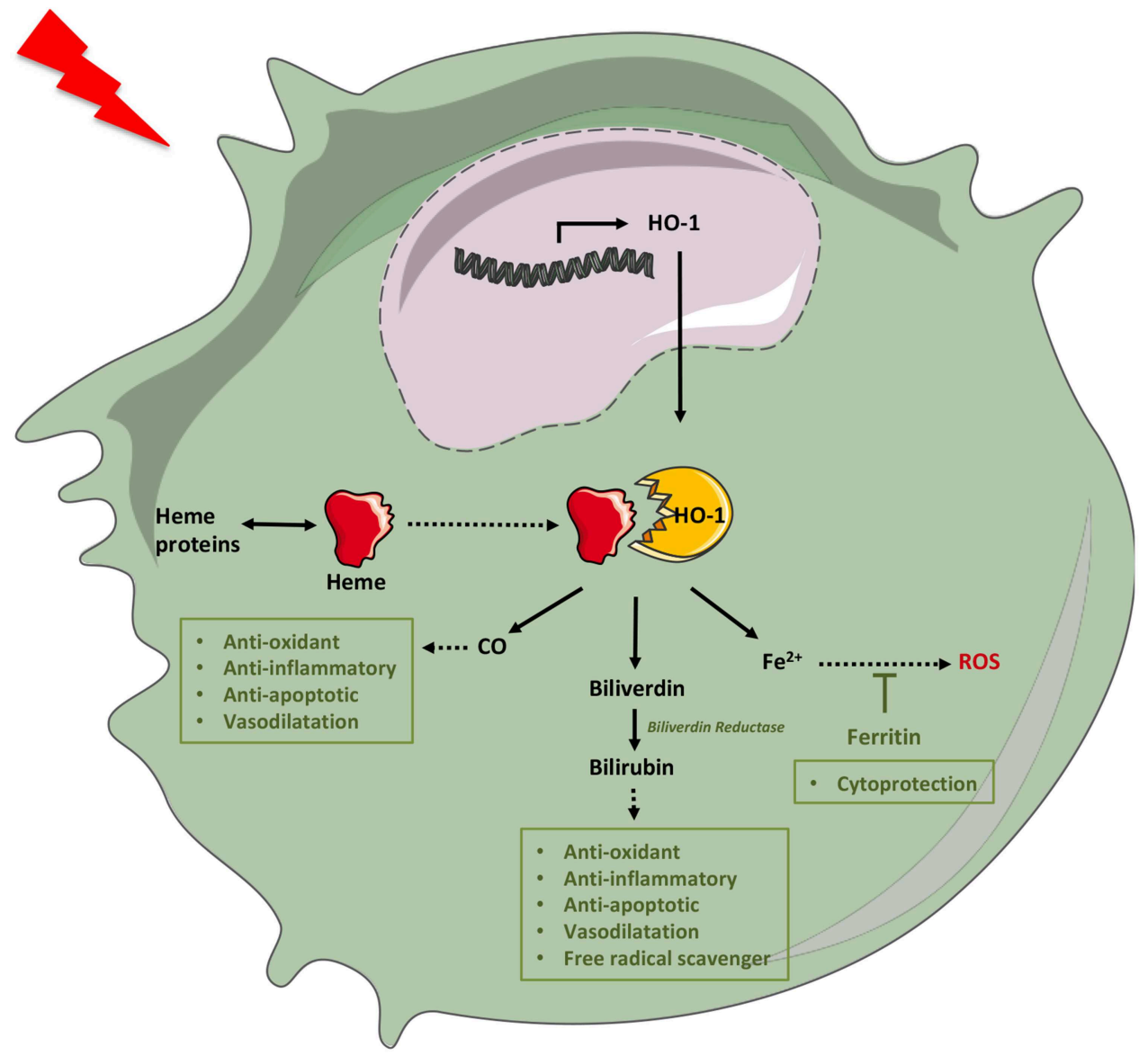

FIGURE 9 | Cytoprotective mechanism of heme oxygenase (HO)-1. Cellular stress and damage release heme that acts as pro-oxidant. Cell injury also induces HO-1 expression through pro-inflammatory signals. $\mathrm{HO}-1$ catabolizes the degradation of heme into free iron (Fe2 $\left.{ }^{+}\right)$, carbon monoxide (CO), and bile pigments (biliverdin), which are converted to bilirubin by the enzymatic action of biliverdin reductase. Bilirubin and CO act as potent antioxidants through NADPH oxidase inhibition and reactive oxygen species (ROS) sequestration. Furthermore, they act as anti-inflammatory, antiapoptotic, and produce vasodilatation. Free iron, a pro-oxidant element, is captured by ferritin, which aids in the cytoprotective mechanisms by reducing ROS generation. (This figure was created using Servier Medical Art templates, which are licensed under a Creative Commons Attribution 3.0 Unported License; https://smart.servier.com).

been in vitro differentiated and our work has been focused on monocytes $(51,53,54)$. Furthermore, phagocytosis is an extremely complex process, and no single model can account for the diverse structures and outcomes associated with the ingestion of particles. Nevertheless, independently of the type of ingested cell and the receptors involved, several common stages of the process have been established: recognition, engulfment, phagosome maturation (phagolysosome), and degradation (55). The pathways involved in the uptake of apoptotic cells by either macrophages or non-professional phagocytes seem to be unique and very highly conserved in evolution (efferocytosis) $(56,57)$. However, there are very few data about the underlying mechanisms that drive apoptotic cell phagosome formation and its consequences for subsequent apoptotic cell digestion. In this study, we evaluated the first step of phagocytosis (engulfed material) and in a short period of time $(60 \mathrm{~min})$. Based on our results, LN monocytes do not have problems in this initial step of phagocytosis, but it seems that the whole process works until it reaches a critical amount of engulfed beads, as shown by the increase in monocytes that phagocyte four or more beads in LN patients. The accumulation of engulfed material inside monocytes could lead or be explained by a delay or a defect in the subsequent steps of phagocytosis, resulting in poor clearance of apoptotic cells, but more experiments are needed to confirm this statement. The modulation of the phagocytic capacity represents a potential therapeutic target in the control of disease, since apoptotic cells, when not efficiently cleared, may represent a source of autoantigens that drive the autoimmune response in SLE (4750). Interestingly, here, we demonstrated that the induction of HO-1 modified the phagocytic activity of LN monocytes to a point that they behave similar to $\mathrm{HC}$ monocytes. We can therefore speculate that defects in the clearance of apoptotic cells by monocytes of LN patients could be in part explained by reduced levels of $\mathrm{HO}-1$, which could contribute to the initiation and maintenance of autoimmunity. Future studies 
designed to investigate the phagocytic pathway would be of interest.

In addition, several studies have shown that high levels of ROS have a role in cellular death in SLE; in fact, elevated ROS production has been associated with increased apoptosis, NETosis, and delayed clearance of apoptotic cells $(58,59)$. Rokutan et al. (58) showed that there are increased oxygen intermediates in the organs of MRL/lpr mice, whereas reduced serum levels of antioxidants and radical scavengers have been reported in human SLE (60). Indeed, treatment with antioxidants, such as vitamin E, suppressed circulating antidsDNA antibody levels and the development of renal disease in MRL/lpr mice $(61,62)$. Different groups have previously shown increased ROS production by LN neutrophils and monocytes. However, there is some controversy in the literature about their response to oxidative stimuli $(63,64)$, arguing that differences in methodology and patient selection may explain some of these. Here, we observed that LN monocytes have elevated ROS levels at baseline, but HO-1 induction reduces these levels to those of $\mathrm{HC}$, exerting their cytoprotective function (65).

Other groups have demonstrated that $\mathrm{HO}-1$ is upregulated in proximal tubular cells in response to oxidative stress and exerts cytoprotective and anti-inflammatory effects in severe cases of sublethal cellular injury affecting tubular segments, which includes ischemia, nephrotoxins, cytokines, endotoxin, oxidants, and vasoactive substances $(66-70)$. To the best of our knowledge, our group and Kishimoto et al. (12) first examined the expression of HO-1 in situ in human $\mathrm{LN}$, focusing on different cell types. Our findings show that HO- 1 expression is increased in tubular epithelium compared with infiltrating cells and is decreased in the epithelium when compared to that in $\mathrm{HC}$, but no significant differences were observed between the biopsies of patients with LN and CC biopsies of patients with kidney cancer probably because although the examined tissue was not infiltrated by tumor, it was stressed tissue exposed to an antitumor immune response. Strikingly, although we studied only three HC biopsies, our findings are consistent with what is seen in peripheral monocytes, which show a decreased expression of HO-1 in LN patients. Further studies to confirm the results observed in human biopsies are needed. While LN has been always classified as a glomerular disease, an increasing body of evidence suggests that tubulointerstitial injury might have a prominent role (66). Our results may suggest that HO-1 presence in RTEC could be an attempt of the kidney to protect itself from damage, which is perpetrated, among others, by innate immune cells showing a low expression of HO-1. Since LN patients might express lower levels of $\mathrm{HO}-1$ than $\mathrm{HC}$, they could be having less protective mechanisms against the damage inflicted by inflammatory cells. Furthermore, the induction of HO-1 in the tubular epithelium in proteinuric states that occurs in cases of LN cannot be simply ascribed to increased trafficking of albumin per se across the proximal tubule; such expression more likely reflects concomitant injury to tubular epithelial cells occurring pari passu with glomerular disease and/or the pro-inflammatory, pro-oxidant, or other perturbing effects of specific proteins or other species appearing in the urinary space, as it has been demonstrated by some authors (67).
In conclusions, we showed that circulating monocytes and activated neutrophils of LN patients have lower levels of HO-1 than those of HC. Although further experiments to demonstrate that these peripheral cells perform tissue damage in LN are needed, our results suggest that this could be the case. In addition, LN monocytes show increased levels of ROS at baseline, and HO-1 induction is able to return HO-1 levels to normal. Thus, decreased HO-1 expression in circulating and infiltrating monocytes and neutrophils of LN patients might promote a pro-inflammatory environment contributing to renal injury. Moreover, we propose that HO-1 induction might exert a cytoprotective role in renal tissue similar to observed in other models of renal injury (68-70) and might regulate innate immunity in LN.

\section{DATA AVAILABILITY STATEMENT}

The raw data supporting the conclusions of this article will be made available upon reasonable request to the corresponding author.

\section{ETHICS STATEMENT}

The studies involving human participants were reviewed and approved by Comité Ético Científico Facultad de Medicina Pontificia Universidad Católica de Chile. The patients/participants provided their written informed consent to participate in this study.

\section{AUTHOR CONTRIBUTIONS}

LC made substantial contributions to the conception and design of the study and drafted the manuscript, performed experimental procedures, made substantial contributions to the analysis and interpretation of data, reviewed the manuscript critically for important intellectual content, and gave final approval of the version to be published. JO participated in the conception and design of the study, performed the qRT-PCR analysis, participated in the analysis and interpretation of data, and revised the final version of the manuscript. PG-M performed immunofluorescence microscopy and histochemical protocol, made substantial contributions to the analysis and interpretation of data, drafted the manuscript and reviewed the manuscript critically for important intellectual content. AV participated in the conception and design of the study, made substantial contributions to the analysis and interpretation of data and reviewed the manuscript critically for important intellectual content. NC participated in the conception and design of the study, performed phagocytosis experiment, participated in analysis of data, drafted the manuscript and reviewed the manuscript critically for important intellectual content. IS participated in the conception and design of the study, performed part of the renal biopsies, participated in the analysis of data, reviewed the manuscript critically for important intellectual content and revised the final version of the manuscript. RV performed experiments, participated in the analysis and interpretation of data, drafted the manuscript, reviewed the 
manuscript critically for important intellectual content, and revised the final manuscript. GM participated in the conception and design of the study, made substantial contributions to the analysis and interpretation of data, drafted the manuscript and reviewed the manuscript critically for important intellectual content. CL participated in the conception and design of the study, made substantial contributions to the analysis and interpretation of data, and drafted the manuscript. All authors read and approved the final version of the manuscript.

\section{REFERENCES}

1. Gottschalk TA, Tsantikos E, Hibbs ML. Pathogenic inflammation and its therapeutic targeting in systemic lupus erythematosus. Front Immunol. (2015) 6:550. doi: 10.3389/fimmu.2015.00550

2. Kulkarni OP, Anders HJ. Lupus nephritis. How latest insights into its pathogenesis promote novel therapies. Curr Opin Rheumatol. (2012) 24:45765. doi: 10.1097/BOR.0b013e328354c877

3. Herrada AA, Llanos C, Mackern-Oberti JP, Carreño LJ, Henriquez C, Gómez RS et al. Haem oxygenase 1 expression is altered in monocytes from patients with systemic lupus erythematosus. Immunology. (2012) 136:414-24. doi: 10.1111/j.1365-2567.2012.03598.x

4. Mackern-Oberti JP, Llanos C, Carreño LJ, Riquelme SA, Jacobelli SH, Anegon I et al. Carbon monoxide exposure improves immune function in lupus prone mice. Immunology. (2013) 140:123-32. doi: 10.1111/imm.12124

5. Zampetaki A, Minamino T, Mitsialis SA, Kourembanas S. Effect of heme oxygenase-1 overexpression in two models of lung inflammation. Exp Biol Med. (2003) 228:442-6. doi: 10.1177/15353702-0322805-02

6. Terry CM, Clikeman JA, Hoidal JR, Callahan KS. TNF-alpha and IL-1alpha induce heme oxygenase-1 via protein kinase $\mathrm{C}, \mathrm{Ca} 2+$, and phospholipase A2 in endothelial cells. Am J Physiol. (1999) 276(5 Pt 2):H1493-501. doi: 10.1152/ajpheart.1999.276.5.H1493

7. Ning W, Song R, Li C, Park E, Mohsenin A, Choi AM et al. TGF-betal stimulates HO-1 via the p38 mitogen-activated protein kinase in A549 pulmonary epithelial cells. Am J Physiol Lung Cell Mol Physiol. (2002) 283:L1094-102. doi: 10.1152/ajplung.00151.2002

8. Choi BM, Pae HO, Jeong YR, Kim YM, Chung HT. Critical role of heme oxygenase-1 in Foxp3-mediated immune suppression. Biochem Biophys Res Commun. (2005) 327:1066-71. doi: 10.1016/j.bbrc.2004.12.106

9. Schumacher A, Wafula PO, Teles A, El-Mousleh T, Linzke N, Zenclussen ML et al. Blockage of heme oxygenase-1 abrogates the protective effect of regulatory $\mathrm{T}$ cells on murine pregnancy and promotes the maturation of dendritic cells. PLoS ONE. (2012) 7:e42301. doi: 10.1371/journal.pone.0042301

10. Hakkim A, Fürnrohr BG, Amann K, Laube B, Abed UA, Brinkmann $\mathrm{V}$, et al. Impairment of neutrophil extracellular trap degradation is associated with lupus nephritis. Proc Natl Acad Sci USA. (2010) 107:9813-8. doi: 10.1073/pnas.0909927107

11. Salmon JE, Millard S, Schachter LA, Arnett FC, Ginzler EM, Gourley MF, et al. Fc gamma RIIA alleles are heritable risk factors for lupus nephritis in African Americans. J Clin Invest. (1996) 97:1348-54. doi: 10.1172/JCI118552

12. Kishimoto D, Kirino Y, Tamura M, Takeno M, Kunishita Y, Takase-Minegishi $\mathrm{K}$, et al. Dysregulated heme oxygenase-1(low) M2-like macrophages augment lupus nephritis via Bach1 induced by type I interferons. Arthritis Res Ther. (2018) 20:64. doi: 10.1186/s13075-018-1568-1

13. Maria NI, Davidson A. Renal macrophages and dendritic cells in SLE nephritis. Curr Rheumatol Rep. (2017) 19:81. doi: 10.1007/s11926-017-0708-y

14. Barrera García A, Gómez-Puerta JA, Arias LF, Burbano C, Restrepo M, Vanegas AL, et al. Infiltrating $\mathrm{CD} 16(+)$ are associated with a reduction in peripheral CD14(+)CD16(++) monocytes and severe forms of lupus nephritis. Autoimmune Dis. (2016) 2016:9324315. doi: 10.1155/2016/9324315

15. Mikolajczyk TP, Osmenda G, Batko B, Wilk G, Krezelok M, Skiba D, et al. Heterogeneity of peripheral blood monocytes, endothelial dysfunction and

\section{FUNDING}

This work was supported by Comisión Nacional de Ciencia y Tecnología, FONDECYT regular $\mathrm{N}^{\circ} 1150173$, Santiago, Chile.

\section{ACKNOWLEDGMENTS}

We would like to thank all SLE patients and HC who participated in this study.

subclinical atherosclerosis in patients with systemic lupus erythematosus. Lupus. (2016) 25:18-27. doi: 10.1177/0961203315598014

16. Mukherjee R, Kanti Barman P, Kumar Thatoi P, Tripathy R, Kumar Das B, Ravindran B. Non-classical monocytes display inflammatory features: validation in sepsis and systemic lupus erythematous. Sci Rep. (2015) 5:13886. doi: 10.1038/srep13886

17. Ziegler-Heitbrock L, Ancuta P, Crowe S, Dalod M, Grau V, Hart DN, et al. Nomenclature of monocytes and dendritic cells in blood. Blood. (2010) 116:e74-80. doi: 10.1182/blood-2010-02-258558

18. Byrne JC, Ní Gabhann J, Lazzari E, Mahony R, Smith S, Stacey K, et al. Genetics of SLE: functional relevance for monocytes/macrophages in disease. Clin Dev Immunol. (2012) 2012:582352. doi: 10.1155/2012/ 582352

19. Li Y, Lee PY, Reeves WH. Monocyte and macrophage abnormalities in systemic lupus erythematosus. Arch Immunol Ther Exp. (2010) 58:355-64. doi: 10.1007/s00005-010-0093-y

20. Sule S, Rosen A, Petri M, Akhter E, Andrade F. Abnormal production of proand anti-inflammatory cytokines by lupus monocytes in response to apoptotic cells. PLoS ONE. (2011) 6:e17495. doi: 10.1371/journal.pone.0017495

21. Yu F, Haas M, Glassock R, Zhao MH. Redefining lupus nephritis: clinical implications of pathophysiologic subtypes. Nat Rev Nephrol. (2017) 13:48395. doi: 10.1038/nrneph.2017.85

22. Obreque J, Vega F, Torres A, Cuitino L, Mackern-Oberti JP, Viviani $\mathrm{P}$, et al. Autologous tolerogenic dendritic cells derived from monocytes of systemic lupus erythematosus patients and healthy donors show a stable and immunosuppressive phenotype. Immunology. (2017)152:648-59. doi: 10.1111/imm.12806

23. Fehlings M, Drobbe L, Moos V, Renner Viveros P, Hagen J, Beigier-Bompadre $\mathrm{M}$, et al. Comparative analysis of the interaction of Helicobacter pylori with human dendritic cells, macrophages, and monocytes. Infect Immun. (2012) 80:2724-34. doi: 10.1128/IAI.00381-12

24. McCarty KS Jr, Miller LS, Cox EB, Konrath J, McCarty KS Sr. Estrogen receptor analyses: correlation of biochemical and immunohistochemical methods using monoclonal antireceptor antibodies. Arch Pathol Lab Med. (1985) 109:716-21.

25. Schneider CA, Rasband WS, Eliceiri KW. NIH Image to ImageJ: 25 years of image analysis. Nat Methods. (2019) 9:671-5. doi: 10.1038/nmeth.2089

26. Mikołajczyk TP, Skrzeczynska-Moncznik JE, Zarebski MA, Marewicz EA, Wiśniewska AM, Dzieba M, et al. Interaction of human peripheral blood monocytes with apoptotic polymorphonuclear cells. Immunology. (2009) 128:103-13. doi: 10.1111/j.1365-2567.2009.03087.x

27. Lakschevitz FS, Hassanpour S, Rubin A, Fine N, Sun C, Glogauer M. Identification of neutrophil surface marker changes in health and inflammation using high-throughput screening flow cytometry. Exp Cell Res. (2016) 342:200-9. doi: 10.1016/j.yexcr.2016.03.007

28. Cai C, Teng L, Vu D, He JQ, Guo Y, Li Q et al. The heme oxygenase 1 inducer (CoPP) protects human cardiac stem cells against apoptosis through activation of the extracellular signal-regulated kinase (ERK)/NRF2 signaling pathway and cytokine release. J Biol Chem. (2012) 287:33720-32. doi: 10.1074/jbc.M112.385542

29. Shan Y, Pepe J, Lu TH, Elbirt KK, Lambrech RW, Bonkovsky HL. Induction of the heme oxygenase-1 gene by metalloporphyrins. Arch Biochem Biophys. (2000) 380:219-27. doi: 10.1006/abbi.2000.1921 
30. Xia ZW, Zhong WW, Xu LQ, Sun JL, Shen QX, Wang JG, et al. Heme oxygenase-1-mediated $\mathrm{CD} 4+\mathrm{CD} 25$ high regulatory $\mathrm{T}$ cells suppress allergic airway inflammation. J Immunol. (2006)177:5936-45. doi: 10.4049/jimmunol.177.9.5936

31. Triantafyllopoulou A, Franzke CW, Seshan SV, Perino G, Kalliolias GD, Ramanujam M, et al. Proliferative lesions and metalloproteinase activity in murine lupus nephritis mediated by type I interferons and macrophages. Proc. Natl. Acad. Sci. USA. (2010) 107:3012-7. doi: 10.1073/pnas.0914 902107

32. Malide D, Russo P, Bendayan M. Presence of tumor necrosis factor alpha and interleukin-6 in renal mesangial cells of lupus nephritis patients. Hum Pathol. (1995) 26:558-64. doi: 10.1016/0046-8177(95)90253-8

33. van de Winkel JG, Capel PJ. Human IgG Fc receptor heterogeneity: molecular aspects and clinical implications. Immunol Today. (1993) 14:21521. doi: 10.1016/0167-5699(93)90166-I

34. Kraaij MD, Vereyken EJ, Leenen PJ, van den Bosch TP, Rezaee F, Betjes MG, et al. Human monocytes produce interferon-gamma upon stimulation with LPS. Cytokine. (2014) 67:7-12. doi: 10.1016/j.cyto.2014.02.001

35. Scapini P, Lapinet-Vera JA, Gasperini S, Calzetti F, Bazzoni F, Cassatella MA. The neutrophil as a cellular source of chemokines. Immunol Rev. (2000) 177:195-203. doi: 10.1034/j.1600-065X.2000.17706.x

36. Bethunaickan R, Sahu R, Liu Z, Tang YT, Huang W, Edegbe O, et al. Anti-tumor necrosis factor $\alpha$ treatment of interferon- $\alpha$-induced murine lupus nephritis reduces the renal macrophage response but does not alter glomerular immune complex formation. Arthritis Rheum. (2012) 64:3399408. doi: 10.1002/art.34553

37. Jacob $\mathrm{CO}$, van der Meide $\mathrm{PH}, \mathrm{McDevitt} \mathrm{HO}$. In vivo treatment of (NZB3NZW)F1 lupus-like nephritis with monoclonal antibody to gamma interferon. J Exp Med. (1987) 166:798-803. doi: 10.1084/jem. 166.3 .798

38. Vijayan V, Wagener FADTG, Immenschuh S. The macrophage heme-heme oxygenase-1 system and its role in inflammation. Biochem Pharmacol. (2018) 153:159-67. doi: 10.1016/j.bcp.2018.02.010

39. Zhu X, Fan WG, Li DP, Kung H, Lin MC. Heme oxygenase-1 system and gastrointestinal inflammation: a short review. World J Gastroenterol. (2011) 17:4283-8. doi: 10.3748/wjg.v17.i38.4283

40. Fagone P, Patti F, Mangano K, Mammana S, Coco M, Touil-Boukoffa C, et al. Heme oxygenase-1 expression in peripheral blood mononuclear cells correlates with disease activity in multiple sclerosis. J Neuroimmunol. (2013) 261:82-6. doi: 10.1016/j.jneuroim.2013.04.013

41. Nath KA, Balla J, Croatt AJ, Vercellotti GM. Heme protein-mediated renal injury: a protective role for 21-aminosteroids in vitro and in vivo. Kidney Int. (1995) 47:592-602. doi: 10.1038/ki.1995.75

42. Bolisetty S, Zarjou A, Agarwal A. Heme oxygenase 1 as a therapeutic target in acute kidney injury. Am J Kidney Dis. (2017) 69:531-45. doi: $10.1053 /$ j.ajkd.2016.10.037

43. Durante W. Protective role of heme oxygenase-1 against inflammation in atherosclerosis. Front Biosci. (2011) 16:2372. doi: 10.2741/3860

44. Tzima S, Victoratos P, Kranidioti K, Alexiou M, Kollias G. Myeloid heme oxygenase-1 regulates innate immunity and autoimmunity by modulating IFN-beta production. J Exp Med. (2009) 206:1167-79. doi: $10.1084 /$ jem. 20081582

45. Soares M, Marguti I, Cunha A, Larsen R. Immunoregulatory effects of HO-1: how does it work? Curr Opin Pharmacol. (2009) 9:482-9. doi: 10.1016/j.coph.2009.05.008

46. Morita $T$, Imai $T$, Yamaguchi $T$, Sugiyama $T$, Katayama $S$, Yoshino G. Induction of heme oxygenase-1 suppresses angiotensin II-elicited chemotactic activity through inhibition of CCR2: role of bilirubin and carbon monoxide generated by the enzyme. Antioxid Redox Signal. (2003) 5:439-47. doi: $10.1089 / 152308603768295186$

47. Casciola-Rosen L, Rosen A, Petri M, Schlissel M. Surface blebs on apoptotic cells are sites of enhanced procoagulant activity: implications for coagulation events and antigenic spread in systemic lupus erythematosus. Proc Natl Acad Sci USA. (1996) 93:1624-9. doi: 10.1073/pnas.93. 4.1624

48. Dieker JW, van der Vlag J, Berden JH. Triggers for antichromatin autoantibody production in SLE. Lupus. (2002) 11:856-64. doi: 10.1191/0961203302lu307rr
49. Berden JH, Licht R, van Bruggen MC, Tax WJ. Role of nucleosomes for induction and glomerular binding of autoantibodies in lupus nephritis. Curr Opin Nephrol Hypertens. (1999) 8:299-306. doi: 10.1097/00041552-199905000-00005

50. Mevorach D, Zhou JL, Song X, Elkon KB. Systemic exposure to irradiated apoptotic cells induces autoantibody production. J Exp Med. (1998) 188:38792. doi: $10.1084 /$ jem.188.2.387

51. Herrmann M, Voll RE, Zoller OM, Hagenhofer M, Ponner BB, Kalden JR. Impaired phagocytosis of apoptotic cell material by monocyte-derived macrophages from patients with systemic lupus erythematosus. Arthritis Rheum. (1998) 41:1241-50. doi: 10.1002/1529-0131(199807)41:7<1241::AID-ART15>3.0.CO;2-H

52. Potter PK, Cortes-Hernandez J, Quartier P, Botto M, Walport MJ. Lupus-prone mice have an abnormal response to thioglycolate and an impaired clearance of apoptotic cells. J Immunol. (2003) 170:3223-32. doi: $10.4049 /$ jimmunol.170.6.3223

53. Ren Y, Tang J, Mok MY, Chan AW, Wu A, Lau CS. Increased apoptotic neutrophils and macrophages and impaired macrophage phagocytic clearance of apoptotic neutrophils in systemic lupus erythematosus. Arthritis Rheum. (2003) 48:2888-97. doi: 10.1002/art.11237

54. Bijl M, Reefman E, Horst G, Limburg PC, Kallenberg CG. Reduced uptake of apoptotic cells by macrophages in systemic lupus erythematosus: correlates with decreased serum levels of complement. Ann Rheum Dis. (2006) 65:57-63. doi: $10.1136 /$ ard.2005.035733

55. Krysko DV, Denecker G, Festjens N, Gabriels S, Parthoens E, D’Herde K, Vandenabeele P. Macrophages use different internalization mechanisms to clear apoptotic and necrotic cells. Cell Death Differ. (2006) 13:2011-22. doi: $10.1038 /$ sj.cdd. 4401900

56. Gardai SJ, McPhillips KA, Frasch SC, Janssen WJ, Starefeldt A, MurphyUllrich JE, et al. Cell-surface calreticulin initiates clearance of viable or apoptotic cells through trans-activation of LRP on the phagocyte. Cell. (2005) 123:321-34. doi: 10.1016/j.cell.2005.08.032

57. deCathelineau AM, Henson PM. final step in programmed cell death: phagocytes carry apoptotic cells to the grave. Essays Biochem. (2003) 39:10517. doi: $10.1042 / b s e 0390105$

58. Rokutan K, Hosokawa T, Nakamura K, Koyama K, Aoike A, Kawai $\mathrm{K}$. Increased superoxide anion production and glutathione peroxidase activity in peritoneal macrophages from autoimmune-prone MRL/Mp-lpr/lpr mice. Int Arch Allergy Appl Immunol. (1988) 87:113-9. doi: 10.1159/000 234660

59. Kurien BT, Scofield RH. Free radical mediated peroxidative damage in systemic lupus erythematosus. Life Sci. (2003) 73:1655-66. doi: $10.1016 /$ S0024-3205(03)00475-2

60. Blount S, Griffiths HR, Lunec J. Reactive oxygen species damage to DNA and its role in systemic lupus erythematosus. Mol Aspects Med. (1991) 12:93-105. doi: 10.1016/0098-2997(91)90005-7

61. Weimann BJ, Weiser H. Effects of antioxidant vitamins C, E, and beta-carotene on immune functions in MRL/lpr mice and rats. Ann NY Acad Sci. (1992) 669:390-2. doi: 10.1111/j.1749-6632.1992.tb 17132.x

62. Weimann BJ, Hermann D. Inhibition of autoimmune deterioration in MRL/lpr mice by vitamin E. Int J Vitam Nutr Res. (1999) 69:255-61. doi: 10.1024/0300-9831.69.4.255

63. Moroni G, Novembrino C, Quaglini S, De Giuseppe R, Gallelli B, Uva $\mathrm{V}$, et al. Oxidative stress and homocysteine metabolism in patients with lupus nephritis. Lupus. (2010) 19:65-72. doi: 10.1177/09612033093 46906

64. Perazzio SF, Salomão R, Silva NP, Andrade LE. Increased neutrophil oxidative burst metabolism in systemic lupus erythematosus. Lupus. (2012) 21:1543-51. doi: $10.1177 / 0961203312461060$

65. Morse D, Choi AM. Heme oxygenase-1: the 'emerging molecule' has arrived. Am J Respir Cell Mol Biol. (2002) 27:8-16. doi: 10.1165/ajrcmb.27.1.4862

66. Yu F, Wu LH, Tan Y, Li LH, Wang CL, Wang WK, et al. Tubulointerstitial lesions of patients with lupus nephritis classified by the 2003 International Society of Nephrology and Renal Pathology Society system. Kidney Int. (2010) 7:820-9. doi: $10.1038 /$ ki.2010.13

67. Pedraza-Chaverri J, Murali NS, Croatt AJ, Alam J, Grande JP, Nath KA. Proteinuria as a determinant of renal expression of heme oxygenase-1: studies 
in models of glomerular and tubular proteinuria in the rat. Am J Physiol Renal Physiol. (2006) 290:F196-204. doi: 10.1152/ajprenal.00230.2005

68. Agarwal A, Balla J, Alam J, Croatt AJ, Nath KA. Induction of heme oxygenase in toxic renal injury: a protective role in cisplatin nephrotoxicity in the rat. Kidney Int. (1995) 48:1298-307. doi: 10.1038/ki.1995.414

69. Nath KA, Balla G, Vercellotti GM, Balla J, Jacob HS, Levitt MD, et al. Induction of heme oxygenase is a rapid, protective response in rhabdomyolysis in the rat. J Clin Invest. (1992) 90:267-70. doi: 10.1172/JCI115847

70. Nath KA. Heme oxygenase-1: a provenance for cytoprotective pathways in the kidney and other tissues. Kidney Int. (2006) 70:432-43. doi: $10.1038 /$ sj.ki.5001565
Conflict of Interest: The authors declare that the research was conducted in the absence of any commercial or financial relationships that could be construed as a potential conflict of interest.

Copyright @ 2019 Cuitino, Obreque, Gajardo-Meneses, Villarroel, Crisóstomo, San Francisco, Valenzuela, Méndez and Llanos. This is an open-access article distributed under the terms of the Creative Commons Attribution License (CC BY). The use, distribution or reproduction in other forums is permitted, provided the original author(s) and the copyright owner(s) are credited and that the original publication in this journal is cited, in accordance with accepted academic practice. No use, distribution or reproduction is permitted which does not comply with these terms. 